\title{
On the Estimation of Total Factor Productivity: A Novel Bayesian Non-Parametric Approach
}

\author{
Mike G. Tsionas ${ }^{\mathrm{a}}$ and Michael L. Polemis ${ }^{\mathrm{b}, \mathrm{c}^{*}}$ \\ ${ }^{a}$ Department of Economics, Lancaster University Management School, LA1 4YX, United \\ Kingdom. \\ b Department of Economics, University of Piraeus, Piraeus, 185 34, Greece ("Corresponding \\ author). Tel: +30 210 4142303; Fax: +30 210 4142346; Email: mpolemis@ unipi.gr. \\ ${ }^{\mathrm{c}}$ Hellenic Competition Commission, Member of the Board, Athens, Greece.
}

\begin{abstract}
This paper provides an alternative general empirical method for the estimation of Total Factor Productivity (TFP). We use a decomposition which allows non-parametric estimation and at the same time addresses the issue of endogeneity of inputs. In this way, we also deal with the unavailability of input prices which is common in the TFP literature. We apply the new techniques to U.S four-digit manufacturing data using a novel Bayesian nonparametric model based on local likelihood. We use Markov Chain Monte Carlo (MCMC) techniques organized around the method of Girolami and Calderhead (2011). We compare and contrast the estimates from the proposed new method with standard parametric methods such as the translog, the Generalized Leontief and the Normalized Quadratic and we also propose novel diagnostic tests for correct specification and validity of instruments. We show that parametric methods lead to biased estimation of TFP growth. Our empirical findings show that the new model passes successfully a battery of robustness checks including diagnostic testing and tests for weak identification as well as weak instruments. Finally policy implications relating to the nature of TFP growth are also provided.
\end{abstract}

Keywords: Manufacturing; Estimation of TFP; Non parametric models; Bayesian analysis; Markov Chain Monte Carlo. 


\section{Introduction}

Since the seminal paper of Robert Solow dated back in 1957, which paved the way and delineated the origins of TFP, there are hundreds of academic papers estimating TFP using an aggregate production function. ${ }^{1}$ TFP growth also known as the Solow residual is the part of output growth that cannot be accounted for by the inputs. In other words, TFP growth is estimated as the residual from the production process after subtracting growth in inputs (labor, capital, energy, etc.) from output growth. Even though the topic might be considered narrow, the literature is quite broad in its relevance, being pertinent to theory and empirical scrutiny alike.

One would expect that this volume of work would have led to some robust conclusions on the magnitude of TFP, and on what factors it depends on. Although a number of important contributions have been made, the basic question of how accurate are the relevant TFP estimates and associated procedures, has provided widely different answers. Part of the reason is that different methodologies provide very different TFP estimates (Biesebroeck, 2008). Additionally, part of the reason may simply come down to differences in the data structure (e.g. data frequency, spatial aggregation, factor prices, or to minor differences in specification such as lag structure).

In addition, some empirical studies (see for example Ang and Kerstens, 2017; Diewert and Fox, 2017; Lansink et al, 2015; Genius et al, 2012; Epure et al, 2011; Rungsuriyawiboon and Stefanou, 2008; Ketteni et al, 2007; Mamuneas et al, 2006) use parametric and non-parametric techniques to estimate directly a production function. However, our concern is that in the absence of factor prices estimating directly a production function yields biased estimators when inputs are endogenous. ${ }^{2}$ There are some approaches to deal with endogeneity but they come with their own constraints. The alternative is to estimate directly a production function. Moreover, in such a situation, where input prices (like output prices) are typically unavailable, quantities of inputs are usually proxied by deflated values of inputs for capital and materials (De Loecker, 2007; Sharma et al, 2007; Kumbhakar and Lovell, 2000).

The alternative is to estimate directly a production function. Moreover, in such a situation, where input prices (like output prices) are typically unavailable, quantities of inputs are usually proxied by deflated values of inputs for capital and materials (De Loecker, 2007; Sharma

\footnotetext{
${ }^{1}$ For a complete survey see Beveren (2012); Syverson, (2011) and Bartelsman, and Doms (2000).

${ }^{2}$ When prices are available, one can use duality theory to estimate a cost function instead of a production function.
} 
et al, 2007; Kumbhakar and Lovell, 2000). However, there are at least three crucial shortcomings with this approach. First, the inputs are endogenous (also known as "simultaneity bias problem") as is well known from previous studies (Tsionas and Izzeldin, 2018; De Loecker, 2007) because under a variety of behavioral assumptions, they are correlated with the productivity component. Second, the specification of the productivity component is difficult and the adoption of parametric assumptions may lead to misleading results. Third, the same is true for a parametric specification of the production function.

To effectively tackle these problems, we propose a new approach to the estimation of TFP growth. This is based on a nonparametric specification of an appropriate equation, along with a novel Bayesian nonparametric local likelihood approach. We use methods of estimation and Bayesian inference based on MCMC to perform the computations. The advantage over estimating a production function can be mostly attributed to two factors. First and foremost, we have a generic decomposition of TFP growth into its five factor input elasticities (i.e. capital services, productive labor, and non-productive labor, energy and raw materials) rather than technological and efficiency change followed by the large body of literature (see among others Olley and Pakes, 1996; Foster et al, 2006; De Loecker and Konings, 2006). This decomposition, does not require functional form specification of a production function. Second, the only component that has to be specified is $\partial F(X, \tau) / \partial \tau$ which, however, is a much easier problem and can be dealt with in the context of nonparametric estimation. For example, one can assume that this partial derivative is independent of input levels, in which case it becomes solely a function of time; a problem that can be solved easily using nonparametric estimation. However, we prefer to avoid this assumption in the present study, assume instead that it depends on input levels, and that the functional form of the dependence is not known in advance. However, the problem of endogenous inputs remains. We address the problem by introducing a novel way amounting to specifying a novel nonparametric multivariate reduced form which relates input levels and input growth rates to a set of instruments. We couple our results with systematic diagnostic tests for correct specification and the validity of instruments.

The paper contributes to the existing literature in many fronts. First and foremost, we use a decomposition which allows non-parametric estimation of TFP and at the same time addresses the issue of endogeneity of inputs, without requiring that input prices are available. Second, we utilize Bayesian techniques organized around Markov Chain Monte Carlo (MCMC). In this way we are able to compare and contrast the estimates from the new method with standard parametric approximations. Third, we propose diagnostic tests for correct specification and validity of 
instruments. To the best of our knowledge, our study is the first that uses a Bayesian approach to the local maximum-likelihood estimator (LML) (see Kumbhakar et al., 2007) organized around the Girolami and Calderhead (2011) MCMC Riemannian Manifold Hamiltonian technique to obtain TFP growth rates estimates. ${ }^{3}$ Fourth, we apply the new techniques to the U.S manufacturing sector. The empirical findings are compared to traditional parametric methods, such as the Generalized Leontief, and Normalized Quadratic production functions, as well as the TFP growth rate calculated from the NBER-CES database.

The rest of the paper is structured as follows. Section 2 describes the literature on the field. In Section 3 the theoretical model of TFP growth is presented, while Section 4 describes the econometric methodology. In Section 5 we present the data and the variables for this study. The empirical application is analyzed in Section 6, along with the necessary sensitivity analysis to check for the robustness of the empirical findings. Moreover, in this section, we provide some policy implications to government officials and market players drawn from the empirical findings of our study. Finally, Section 7 concludes the paper.

\section{Literature review}

There are two different strands in the productivity analysis literature, namely the standard approach and the frontier approach. The first one is based on standard neoclassical production function models as first developed by Solow (1956). However, the greatest weakness of using the Solow residual is that it does not decompose sources of TFP growth stemming from technological progress or from efficiency gains (Sharma et, al, 2007). The second approach (see for example Atkinson et al, 2003; Narasimham, et al, 1988) can be implemented by either mathematical programming techniques (Data Envelopment Analysis, DEA) or econometric modelling (Stochastic Frontier Analysis, SFA).

TFP growth is often used by the researchers and practitioners to assess the impact of various micro and macro-economic policies such as the extent of foreign ownership (Javorcik, 2004), trade openness (Pavcnik, 2002; Amiti and Konings, 2007; De Loecker, 2011), antidumping protection (Konings and Vandenbussche, 2008). The decomposition of TFP growth has also received considerable interest in applied research (see for example Olley and Pakes, 1996; Foster et al, 2006; De Loecker and Konings, 2006). Indeed, most of the parametric studies

\footnotetext{
${ }^{3}$ For an application of the local linear maximum likelihood estimator to banking industry see Tsionas and Mamatzakis, (2017).
} 
employ a translog functional form without any prior tests. However, this raises serious doubts about the validity of findings and policy implications as parametric models rely on strong assumptions of the functional form (Delis et, al, 2014; Polemis and Stengos, 2015; Tran and Tsionas, 2010).

To overcome the simultaneity bias problem described above, Olley and Pakes (1996) developed a semi-parametric estimator by using the firm's investment decision to proxy for unobserved TFP growth rate (see also Beveren, 2012). This approach has generated many interesting contributions in the field (see for example Ackerberg et al, 2015; Foster et al. 2008; Eslava et al, 2004; Mairesse and Jaumandreu, 2005). A major problem is that often investment is zero and the required invertibility conditions do not hold.

Levinsohn and Petrin (2003) follow a different approach in solving the endogeneity problem. In contrast to Olley and Pakes, they use intermediate inputs (materials) rather than investment as a proxy for unobserved productivity. Hence, intermediate inputs are expressed as a function of capital and productivity (Beveren, 2012). Moreover, this approach does not incorporate the survival probability in the second stage as Olley and Pakes (1996) do. However, both the Olley-Pakes and Levinsohn-Petrin approach can be used only along with a CobbDouglas specification which, in empirical practice, is quite restrictive.

Estimating and decomposing TFP for the US at a national or at a regional level (i.e. states) has been thoroughly examined by researchers within the last years. Specifically, Beeson and Husted (1989) examine manufacturing across U.S. states and what determines differences in this sector's efficiency. Moreover, Puig-Junoy (2001) and Brock (2001) use SFA to measure efficiency differences across U.S. states. Similarly, Sharma et. al. (2007) employed SFA to decompose the sources of TFP growth rates among a sample of the 48 contiguous U.S. states over the period 1977-2000. They argue that technological progress comprises the majority of TFP growth, and that differences in efficiency change explain cross-state differences in TFP growth. Their findings reveal that the largest (smallest) states are associated with higher (lower) labor elasticities and lower (higher) capital elasticities.

In another study İmrohoroğlu and Tüzel (2014) estimate firm-level productivity using the semiparametric method of Olley and Pakes (1996) and construct a panel of TFP levels for publicly traded firms in the US. They argue that low productivity firms have, on average, higher excess returns than high productivity firms. Cardarelli and Lusine, (2015) estimate state-level TFP growth using two different methodologies. First, they estimate parametrically a CobbDouglas production function with time-varying and state-specific labor shares. Second, they 
employ a SFA to decompose TFP growth rates into technological trends and technical efficiency at a state level.

Based on the above, we conclude that estimating TFP has become of interest to economists in a number of playing fields which, along with the availability of data especially at the individual establishment level (firm), helped spawn a vast empirical literature and also a number of important theoretical contributions. This literature spans nearly fifty years, uses data at various level of aggregation, covers periods of a few years to longer than a decade, ranges in frequency, considers both parametric and non-parametric techniques ranging from simple estimators such as OLS fixed effects, instrumental variables and GMM to complicated semiparametric forms (see inter alia Olley and Pakes, 1996; Domazlicky and Weber, 1997; Levinsohn and Petrin, 2003) or even panel threshold techniques (Chen et al., 2018). Specifically, Grosskopf, et al., (1994); and Ray and Desli (1997) construct Malmquist productivity indexes for OECD countries using mathematical programming techniques. Domazlicky and Weber (1997) estimate TFP growth rates for a sample of 48 US contiguous states using the same techniques. In another study Van Biesebroeck (2007) compares the robustness of five commonly used techniques (index numbers, DEA, SFA, GMM and semi-parametric methodologies) to estimate TFP growth rates in the presence of measurement error and differences in production technology.

\section{The theoretical model}

Suppose we have a production function of the form:

$$
Q=F\left(X_{1}, \ldots, X_{K}, \tau\right),
$$

where $Q$ is output, $X_{1}, \ldots, X_{K}$ are factors of production and $\tau$ denotes time. If factor prices (relative to the price of output) are denoted by $W_{1}, \ldots, W_{K}$ then we have:

$$
Q=\sum_{k=1}^{K} W_{k} X_{k}
$$

as in Hsieh (1999) and Chen et al, (2018). Taking log derivatives with respect to time, after some algebra we obtain:

$$
\dot{Q}=\sum_{k=1}^{K} s_{k}\left(\dot{W}_{k}+\dot{X}_{k}\right)
$$


where $s_{k}$ is the cost share of the $k$ th input: $s_{k}=\frac{W_{k} X_{k}}{\sum_{k^{\prime}=1}^{K} W_{k^{\prime}} X_{k^{\prime}}}$ and, generically, $\dot{x}=\frac{d \ln x}{d \tau}$. If we rearrange terms, we have the following expression:

$$
\dot{Q}-\sum_{k=1}^{K} s_{k} \dot{X}_{k}=\sum_{k=1}^{K} s_{k} \dot{W}_{k}
$$

The left-hand-side of this equation provides TFPG, the rate of growth of total factor productivity (Acemoglu, 1999). If we take log derivatives of the production function with respect to time we obtain:

$$
\frac{d \ln Q}{d \tau}=\sum_{k=1}^{K} \frac{\partial \ln F}{\partial \ln X_{k}} \dot{X}_{k}+\frac{\partial \ln F}{\partial \tau}
$$

Suppose $\varepsilon_{k}=\frac{\partial \ln F}{\partial \ln X_{k}}$. Then we have:

$$
\frac{d \ln Q}{d \tau}=\sum_{k=1}^{K} \varepsilon_{k} \dot{X}_{k}+\mathcal{T}(X, \tau)
$$

where $\mathcal{T}(X, \tau)=\frac{\partial \ln F(X, \tau)}{\partial \tau}$ and $X=\left(X_{1}, \ldots, X_{K}\right)$.

We start from equation (2) which we re-write here in the case of panel data:

$$
\dot{Q}_{i t}=\sum_{k=1}^{K} \varepsilon_{k} \dot{X}_{k, i t}+\mathcal{T}\left(X_{i t}, \tau_{i t}\right), i=1, \ldots, n, t=1, \ldots, T
$$

where $\tau_{i t}=t, \mathcal{T}\left(X_{i t}, \tau_{i t}\right)=\frac{\partial \ln F\left(X_{i t}, \tau_{i t}\right)}{\partial \tau_{i t}}$ and $F\left(X_{i t}, \tau_{i t}\right)$ is the production function. If we define $\dot{X}_{i t}=\left[\dot{X}_{1, i t}, \ldots, \dot{X}_{K, i t}\right]^{\prime}$ we can write this equation as:

$$
\dot{Q}_{i t}=\dot{X}^{\prime}{ }_{i t} \varepsilon+\mathcal{T}\left(X_{i t}, \tau_{i t}\right), i=1, \ldots, n, t=1, \ldots, T,
$$

where $\varepsilon=\left[\varepsilon_{1}, \ldots, \varepsilon_{K}\right]^{\prime}$. Provided we can estimate this equation, we can obtain an estimate of TFP growth (TFPG) as follows: 


$$
T F P G=\left(1-\frac{1}{E_{i t}}\right) \dot{X}^{\prime}{ }_{i t} \varepsilon+\mathcal{T}\left(X_{i t}, \tau_{i t}\right), i=1, \ldots, n, t=1, \ldots, T,
$$

where $E$ is the elasticity of production, viz. $E_{i t}=\sum_{k=1}^{K} \frac{\partial \ln F\left(X_{i t}, \tau_{i t}\right)}{\partial \ln X_{k, i t}}=\sum_{k=1}^{K} \varepsilon_{k, i t}$.

It is necessary to highlight that "when price information is not available to determine costs, the allocative efficiency component [the last term in Eq. 4] cannot be calculated empirically" (Sharma, et al, 2007). In this case, as proposed by Kumbhakar and Lovell (2000) we assume that the input's share in production costs (input factor shares) equals the output elasticity of the $\mathrm{i}^{\text {th }}$ input.

Estimation of (4) does not make it necessary to specify a parametric specification of the production function. All that is involved is (nonparametric) specification of the productivity or technical change component $\mathcal{T}\left(X_{i t}, \tau_{i t}\right)$, which is, admittedly, a much easier problem. In practice we approximate $\dot{Q}_{i t}$ as: $\dot{Q}_{i t}=\frac{Q_{i t}-Q_{i, t-1}}{\frac{1}{2}\left(Q_{i t}+Q_{i, t-1}\right)}$, and we follow the same practice for each $\dot{X}_{k, i t}$ $(k=1, \ldots, K)$. For the model:

$$
\dot{Q}_{i t}=\sum_{k=1}^{K} \varepsilon_{i, k} \dot{X}_{k, i t}+\mathcal{T}\left(X_{i t}, \tau_{i t}\right)+v_{i t},
$$

we approximate the unknown function $\mathcal{T}\left(X_{i t}, \tau_{i t}\right)$ with a linear function:

$$
\mathcal{T}\left(X_{i t}, \tau_{i t}\right)=\beta_{o}+\beta_{1}^{\prime} X_{i t}+\beta_{2} \tau_{i t} \equiv \beta_{0}+\beta^{\prime} W_{i t}
$$

where $W_{i t}=\left[X_{i t}^{\prime}, \tau_{i t}\right]^{\prime}$. The specification in (7) is a linear function of factor inputs and time. This suggests that technical change is disembodied, or Hicks neutral (see Blackorby et al, 1976). ${ }^{4}$ In other words, the passage of time affects variable inputs in the same way (Genious et, al, 2012). The Hicks-neutrality technical change hypothesis can be statistically tested (e.g. conventional likelihood ratio tests can be applied) by imposing the restriction $\beta=\mathbf{0}$. Although linearity in (7)

\footnotetext{
${ }^{4}$ This corresponds to a situation where, with any given input proportions, the average and marginal products of all inputs increase in the same proportion (Varian, 1992). Thus if $Y=F(K, L)$, and the function $\mathrm{F}(\mathrm{K}, \mathrm{L})$ has constant returns to scale, output after Hicks-neutral technical progress is given by $\mathrm{Y}^{*}$ $=\mathrm{F}(\lambda \mathrm{K}, \lambda \mathrm{L})=\lambda \mathrm{F}(\mathrm{K}, \mathrm{L})=\lambda \mathrm{Y}$.
} 
is, apparently, highly restrictive it is quite helpful as we will make the coefficients arbitrary functions of $X_{i t}$ and $\tau_{i t}$. Therefore, the model becomes:

$$
\dot{Q}_{i t}=\beta_{0}+\dot{X}^{\prime}{ }_{i t} \varepsilon_{i}+\beta_{1}\left(W_{i t}\right)^{\prime} X_{i t}+\beta_{2}\left(W_{i t}\right) \tau_{i t}+v_{i t},
$$

where $W_{i t}=\left[X_{i t}^{\prime}, \tau_{i t}\right]^{\prime}$, and $\beta_{1}\left(W_{i t}\right)$ and $\beta_{2}\left(W_{i t}\right)$ are arbitrary functions of $W_{i t}$. The exact specification of these functions will be discussed in the next section.

We model endogeneity using a reduced form:

$$
\psi_{i t} \triangleq\left[\begin{array}{c}
\dot{X}_{i t} \\
X_{i t}
\end{array}\right]=\Pi\left(I_{2 K} \otimes \tilde{W}_{i t}\right)+\tilde{V}_{i t},
$$

where $\tilde{V}_{i t}$ is a vector random variable, $\tilde{W}_{i t}$ is a $d \times 1$ vector of instruments and $\Pi$ is a matrix of coefficients. We assume:

$$
\left[\begin{array}{c}
v_{i t} \\
\tilde{V}_{i t}
\end{array}\right] \sim N_{2 K+1}(0, \Sigma) .
$$

Moreover, we assume $\Sigma=C^{\prime} C$ where $C$ is a lower triangular matrix. Although the reduced form is linear and has normally distributed error terms, we will use the local likelihood approach developed by Kumbhakar et al, (2007), to convert it to a full nonparametric model. The latter is fully described in the next section.

\section{Empirical framework}

\subsection{Local likelihood}

Before proceeding we need the likelihood function of the model expressed as follows:

$$
f\left(Y_{i t} ; \theta, \varepsilon, W_{i t}\right)=(2 \pi)^{-(2 K+1) n T / 2}|\Sigma|^{-n T / 2} \exp \left\{-\frac{1}{2} U_{i t}^{\prime}(\theta, \varepsilon) \Sigma^{-1} U_{i t}(\theta, \varepsilon)\right\},
$$

where:

$$
U_{i t}(\theta, \varepsilon)=\left[\begin{array}{l}
\dot{Q}_{i t}-\beta_{o} \dot{X}^{\prime}{ }_{i t} \varepsilon_{i}-\beta_{1}^{\prime} X_{i t}-\beta_{2} \tau_{i t} \\
\psi_{i t}-\Pi\left(I_{2 K} \otimes \tilde{W}_{i t}\right)
\end{array}\right] .
$$


The parameters of the model are $\beta_{o}, \beta_{1}, \beta_{2}, \Pi, \Sigma$ (or equivalently $C$ ) and $\varepsilon=\left\{\varepsilon_{i}, i=1, \ldots, n\right\}$. Due to the potentially large number of $\varepsilon_{i}$ s we assume they are fixed but different for different units in the cross-section. The vector of varying parameters is $\theta=\left[\beta_{o}^{\prime}, \beta_{1}^{\prime}, \beta_{2}^{\prime}, \operatorname{vec}(\Pi)^{\prime}, \operatorname{vech}(C)^{\prime}\right]^{\prime}$. In the local likelihood approach we assume that $\theta$ is a function of $w$, the vector at which we want to estimate the unknown function (this vector contains $\left.X_{i t}, \tau_{i t}\right)$. Using a local linear estimator, we have: $\theta(w)=\theta_{o}+\Theta_{1}\left(W_{i t}-w\right)$ so that $\theta(w)=\theta_{o}$ when $w=W_{i t}$.

The log likelihood function for a local linear model can be written as:

$$
\log L_{w}\left(\theta_{o}, \Theta_{1}, \varepsilon ; D\right)=\sum_{i=1}^{n} \sum_{t=1}^{T} \log f\left(Y_{i t} ; \theta_{o}+\Theta_{1}\left(W_{i t}-w\right), \varepsilon, W_{i t}\right) K_{H}\left(W_{i t}-w\right)
$$

where $\theta_{o}, \Theta_{1}$ are $k \times 1$ and $k \times d, H$ is a bandwidth matrix and $K_{H}(u)=|H|^{-1} K\left(H^{-1} u\right)$ where $K(z)=\prod_{j=1}^{d} K_{1}(z)$ for some univariate kernel $K_{1}(z)$. We denote the data by $D=\left[Y_{i t}, W_{i t} ; i=1, \ldots, n, t=1, \ldots, T\right]$. In this case we have:

$$
\int u u^{\prime} K(u) d u=\left(\int u_{1}^{2} K_{1}\left(u_{1}\right) d u_{1}\right) I_{d} .
$$

The local linear estimator is

$$
\hat{\theta}(w)=\hat{\theta}_{o}(w)
$$

where $\hat{\theta}_{o}(w)$ and $\hat{\Theta}_{1}(w)$ maximize $\log L_{w}\left(\theta_{o}, \Theta_{1}, \varepsilon ; D\right)$.

As in Kumbhakar et al, (2007), we choose $H=h S_{W} n^{-1 / 5}$ where $S_{W}$ is the vector of standard deviation of variables in $W_{i t}$ and $h$ is a $d$-dimensional vector of bandwidths. Then, the product kernel becomes: $h^{-d} \prod_{j=1}^{d} K_{1}\left(h^{-1} W_{j, i t}\right)$. Therefore, the bandwidth parameter $h$ is adjusted to account for different scales and sample sizes. We treat $h$ as an unknown parameter and it is subjected to formal statistical inference, along with the remaining parameters, within our Bayesian framework. This replaces the need for cross - validation. We use $X_{i, t-1}, \dot{X}_{i, t-1}$, and a 
time trend as instruments. Squares and interactions of all these variables are included in the list of instruments. To capture the impact of market structure on TFP we use as instrument the level of concentration ratio of the four largest industries in each sector (CR4), its square and its interactions with $X_{i t}, \dot{X}_{i t}$, and the time trend. To estimate TFP growth we use the following:

$$
T F P G_{i t}=\left(1-E_{i}^{-1}\right) \sum_{k=1}^{K} \varepsilon_{i k} \dot{X}_{k, i t}+\mathcal{T}\left(X_{i t}, \tau_{i t}\right)
$$

where the elasticities $\varepsilon_{i k}$ and the unknown function $\mathcal{T}\left(X_{i t}, \tau_{i t}\right)$ have been estimated through the local likelihood approach whose Bayesian variant is proposed next.

\subsection{Bayesian Local Likelihood}

As indicated above, the main contribution of this study is to provide a new method for the estimation of TFP. More specifically, to avoid making strong assumptions about the functional form, a non-parametric specification for the production function is estimated using MCMC methods, also accounting for endogeneity of factor inputs. The technique is applied to U.S. fourdigit manufacturing data over the period 1958-2007. Compared to traditional parametric methods, the new method results in a distribution of TFP growth rates that shows a relatively better fit when compared to the five-factor productivity measure calculated from the NBER-CES database. As the latter is assumed to be the "true" TFP (despite the assumption of constant returns to scale), we argue that the proposed method provides much better estimates of the TFP growth rate compared with GMM estimates from the translog parametric model.

The local likelihood may exhibit multimodality which, in turn, may provide a local optimum instead of a global maximum. Moreover, the parameters may be highly correlated making difficult the use of standard optimization tools such as variants of Newton - Raphson. For this reason, we resort to a Bayesian approach in this paper.

In the Bayesian approach we consider the posterior given by Bayes' theorem:

$$
p\left(\theta_{o}, \Theta_{1}, \varepsilon, h \mid D\right) \propto L_{w}\left(\theta_{o}, \Theta_{1}, \varepsilon ; D\right) p\left(\theta_{o}, \Theta_{1}, \varepsilon, h\right),
$$


where $p\left(\theta_{o}, \Theta_{1}, \varepsilon\right)$ denotes the prior. The bandwidth parameter $(h)$ is included in the parameter vector. Our prior on all parameters $\theta_{o}, \Theta_{1}$ is flat subject to the only restriction that the elasticities are in the interval $(0,1)$ to take account of the economic restrictions of the model. For the bandwidth parameter we use an improper prior of the form:

$$
\begin{gathered}
p\left(\theta_{o}, \Theta_{1}, \varepsilon, h\right) \propto p\left(\theta_{o}, \Theta_{1}, \varepsilon \mid h\right) p(h), \\
p(h) \propto h^{-1},
\end{gathered}
$$

to reflect prior ignorance about values of this parameter. Moreover

$$
p\left(\theta_{o}, \Theta_{1}, \varepsilon\right) \propto I_{(0,1)^{K}}(\varepsilon),
$$

where $I$ denotes the indicator function. Avoiding cross - validation to determine the bandwidth parameters is a significant advantage of the approach and results in computational savings of considerable magnitude at the cost of one extra parameter $(h)$.

We use the MCMC method of Girolami and Calderhead (2011) to obtain draws from the posterior. The technique uses first and second derivative information from the posterior and provides a thorough exploration of the likelihood / posterior. To estimate derivatives of the form $\frac{\partial T F P G_{i t}}{\partial X_{k i t}}, k=1, \ldots, K$, which are of central interest in our analysis, we use the local coefficients obtained from (16) fixing all variables at their medians and evaluating the local coefficients at a grid of 100 points for $X_{k i t}$ running from its minimum to maximum value. For purposes of presentation and ease of comparisons, in our plots, we normalize this interval to $[0,1]$. These derivatives are of central interest as they allow a "decomposition" of TFP growth. Estimation details, organized around Bayesian techniques using MCMC, are provided in Appendix A.1.

\section{Data and variables}

Similarly to Chen et al. (2018), the sample consists of a data set of United States manufacturing industries at the four-digit level $(\mathrm{N}=459)$ over the five-year period 1958-2007 ( $\mathrm{T}=13)$, so giving an unbalanced panel of 4,361 observations. The sample period was strictly dictated by data 
availability since most of the variables used in the empirical application was missing for the year 2012. Similarly to other empirical studies (see for example Serpa and Krishnan, 2017), all variables are taken from the National Bureau of Economic Research (NBER) and especially from the Manufacturing Industry Database (NBER-CES) which contains annual data from the United States manufacturing sector for the period from 1958 to $2011 .^{5}$

Specifically, we use the total value of shipments per sector as a proxy for total output (Q). For variable inputs, we use: production worker hours $(\mathrm{N})$; non-production worker hours $(\mathrm{L})$; capital expenditure $(\mathrm{K})$ as a proxy for capital services ${ }^{6}$; cost of electricity and fuels $(\mathrm{E})$ that serves as a proxy for cost of energy and cost of non-energy materials (M-E) as a proxy for intermediate inputs. ${ }^{7}$ The above variables are denominated in millions of nominal dollars, except for labor variables that are denominated in thousands of workers or millions of worker hours. To convert nominal dollars to real ("fixed-base") dollars and calculate productivity factors, four different deflators are used $(1997=100)$ accounting for value of shipments, material cost, energy and capital expenditure.

As mentioned, we also include the concentration ratio of the four largest industries in each sector (CR4) as an instrument to account for the impact of market structure on the production process and allow for certain cyclical behavior (nonlinearities) in the effect of the covariates on the dependent variable (see Polemis and Stengos, 2015). Finally, the sample includes a five-factor productivity measure (TFP5) which is used as a benchmark in our empirical analysis. The latter comprises of capital $(\mathrm{K})$, production worker hours $(\mathrm{N})$, non-production worker hours (L), energy (E) and non-energy materials (M-E). The five-factor productivity measure drawn from the NBER-CES database is calculated as follows:

\footnotetext{
${ }^{5}$ The data used for the construction of the database come from various sources, but chiefly from three government agencies: a) The U.S. Census Bureau, b) The Bureau of Economic Analysis (BEA), and c) The Bureau of Labor Statistics (BLS).

${ }^{6}$ Notably, the use of capital services (as opposed to capital stock) is quite uncommon in the literature, although it is, apparently, the correct way to proceed.

${ }^{7}$ In alignment with other studies (Polemis and Stengos, 2015; Becker et al, 2016; Chen et al, 2018) we used total value of shipments as a proxy for total manufacturing output. Moreover, we have also used the real capital expenditure (flow variable) as a proxy for capital (stock variable) due to data constraints on the capital stock variable (see also Polemis and Stengos, 2015, Serpa and Krishnan, 2017, Chen et al, 2018). The sample variable, includes "permanent additions and major alterations to the plant structures along with the new machinery and equipment. In other words it combines spending on structures and equipment and does not include used plant and equipment, land, or maintenance or repair expenses" (Bartelsman and Gray, 1996).
} 


$$
T F P 5=\hat{Q}-\sum_{i} a_{i} \hat{X}_{i}, i=K, N, L, E, M,
$$

where $Q$ is real output, $a_{i}$ is the average share (current and lagged year) of factor $i$ relative to industry shipments, $X_{i}$ is the real input of factor $i$, and ${ }^{\wedge}$ denotes the first difference of the logarithm (growth rate). The share of capital is computed as one minus the sum of the other factor shares (see Becker et al, 2016). Summary statistics for the data used in the empirical application are listed in Table 1.

Table 1: Summary statistics

\begin{tabular}{lcccc}
\hline Variables & Mean & Std. dev & Min & Max \\
\hline & & & & \\
TFP5 & 1.016 & 1.049 & 0.161 & 49.04 \\
Q & 7,411 & 77,398 & 17.000 & $3,288,454$ \\
N & 444.9 & 898.8 & 4.100 & 14,794 \\
L & 293.1 & 667.9 & 0.900 & 8,803 \\
K & 2,437 & 5,971 & 3.700 & 79,776 \\
E & 116.5 & 370.6 & 3.000 & 6,442 \\
M-E & 2,882 & 8,219 & 4.000 & 177,247 \\
CR4 & 40.32 & 43.56 & 6.000 & 99.3
\end{tabular}

Note: The table reports summary statistics for the actual data. TFP5, is the five factor Total Factor Productivity index $(1997=1.000)$ as estimated by the NBER-CES. Q is the value of shipments expressed in real terms. $\mathrm{N}$ stands for the production worker hours, while $\mathrm{L}$ denotes the non-production worker hours. $\mathrm{K}$ stands for the real total capital expenditure. $\mathrm{E}$ is the real cost of electricity and fuels, while M-E denotes the real total cost of materials (energy excluded). Finally, CR4 denotes the sum of the market shares of the four largest firms in each of the sample sectors.

\section{Results and discussion}

This section presents and discusses our main empirical findings. Moreover, we report and analyze the estimation results from the Bayesian local likelihood ("new model") estimated by applying Bayesian techniques around MCMC approach. We also compare these results with the actual TFP 
growth rates obtained by NBER and the standard parametric methods. We use a translog model as well as the Normalized Quadratic and Generalized Leontief models. This section presents also the necessary diagnostic tests for correct specification and validity of instruments used from the MCMC procedure. Our MCMC implementation of Girolami and Calderhead (2011) uses 150,000 iterations the first 50,000 of which are discarded to mitigate the possible impact of startup effects. Convergence was found to occur during the transient or burn-in phase using Geweke's (1992) diagnostics.

\subsection{Empirical findings}

We start our analysis by applying a baseline model to use it as our main point of reference (benchmark). Specifically, we use a flexible translog approximation which includes capital services, productive labor, non-productive labor, energy, materials (excluding energy), a time trend and their squares and interactions (cross-terms). We also consider alternative parametric forms for the production function, such as the log linear (Cobb-Douglas), the Generalized Leontief (GL) and the Normalized Quadratic (NQ). A common feature of these models is that they rely on strong assumptions of the functional form, usually without a prior analysis of the properties of the data (Delis et al., 2014). In any case, all parametric approximations may lead to erroneous estimation of TFP growth rates. ${ }^{8}$

To deal with the endogeneity problem is essential because otherwise the translog model would have been just a convenient straw man. For this reason, the endogenous variables (i.e. the factors of production) are regressed on all instruments and their residuals are included in the estimated translog production function). This method described in Terza et al. (2008) is known as "two-stage residual inclusion" (2SRI) and it can be shown to be a parametric correction for endogeneity. Productivity growth can be measured, in turn, using the derivative of the translog production function with respect to the time trend. This partial derivative depends on time as well as the values of the factors of production. Moreover, the translog is a second-order approximation to an arbitrary production function (around the means of the logs of the data) and is widely used in applied production studies (see Christensen, et al, 1971; 1973). The simplest translog production function takes the following form:

\footnotetext{
${ }^{8}$ The results from the Cobb-Douglas specification are available from the authors upon request. The results from the other parametric functional forms are presented in sub-section 6.3
} 
$\ln Q=\ln A_{a i, \beta i j}+\sum_{i=1}^{5} a_{i} \ln X_{i}+\frac{1}{2} \sum_{i=1}^{5} \sum_{j=1}^{5} \beta_{i j} \ln \mathrm{X}_{i} \ln \mathrm{X}_{j}$

Having discussed the primal problem, we begin our empirical analysis by estimating the above translog production function with the Generalised Method of Moments (GMM) to account for the endogeneity of inputs. Figure 1, reports the posterior marginal density or probability density function (PDF) of TFP estimates of the two models (new model vs translog) with the equivalent of the "true" TFP growth rate (actual data) obtained by the NBER-CES database. A careful inspection of Figure 1 provides some important points. Specifically, the sample distribution of TFP growth rate (actual data) is close to being symmetric although apparently nonnormal. Moreover, the results from the baseline parametric (translog) model illustrate that GMM generates TFP growth rate estimates that substantially deviate from "true" TFP to a larger degree than the non-parametric counterpart (new model).

Figure 1. Sample density of TFP growth (Actual data vs new model and translog)

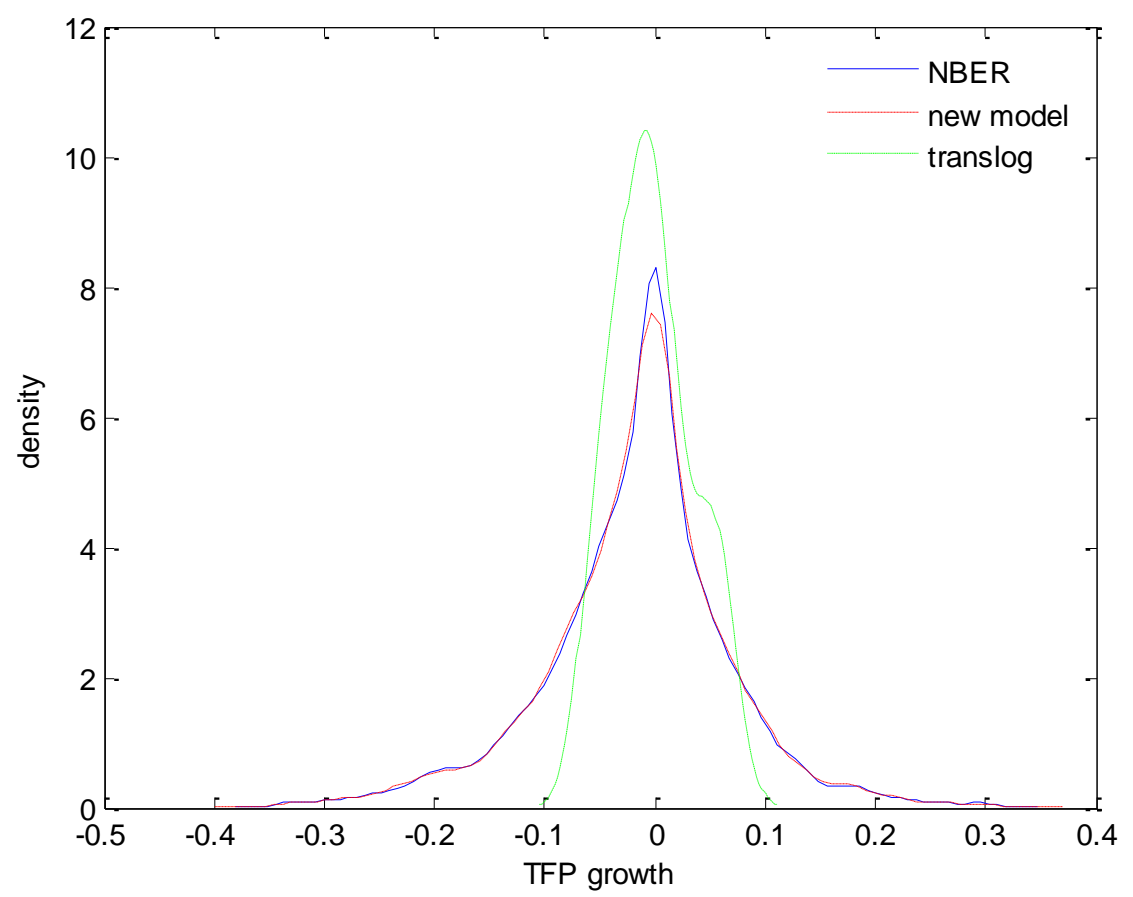

Source: Authors' estimations.

Although we present the baseline model, it is worthwhile to compare estimates of median TFP growth rates across industries and time, accounting for parametric (translog), non-parametric (new model) estimations with the actual NBER measure. In Figure 2, we present estimates of TFP 
growth from the new model, a parametric translog specification which we use as a useful benchmark and also the five-factor productivity measure (TFP5) extracted by NBER (actual data). Some striking results emerge. First, there is significant variation between the translog model and the actual data (NBER). Specifically, the NBER data provide TFP growth rates are characterized by an upward trend throughout the sample period (1958-2007).

This trend is interrupted in 1979 and 1997 due to the impact of exogenous shocks such as the second oil crisis (1979) and the financial crisis that hit many Asian markets (Hong Kong, Taiwan, Thailand, South Korea, etc) within the period 1997-1998 (Jerzmanowski, 2007; Sharma, et, al, 2007). Indeed, the translog model depicts a totally reversed pattern compared with the NBER estimates, showing that despite its flexibility and simplicity in its estimation it is not suitable for policy making. This outcome concurs with the above findings revealing that nonparametric techniques in estimating TFP growth rates may be most suitable for researchers and government officials.

Figure 2. Median TFP growth rates across industries over time (1958-2007)

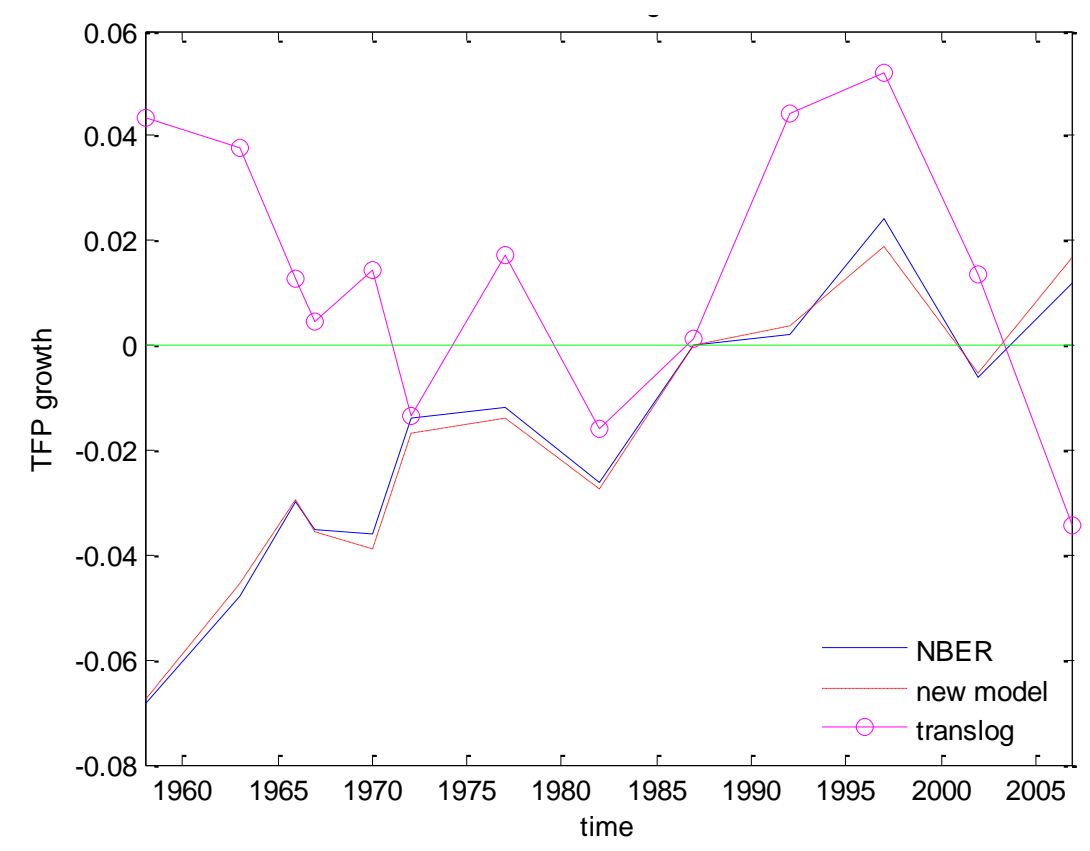

Source: Authors' estimations.

A different situation presents itself when we examine TFP growth rates of the new model estimated at the median of the distribution across the whole sample (four-digit industries over the period 1958-2007). Specifically, the new model provides a good fit to the data, which may be 
attributed to the fact that in contrast to the parametric models which rely on strong assumptions about functional forms, non-parametric techniques do not impose ex ante assumptions such as the type of technology used and the limits of the industry.

Having estimated and contrasted the posterior distribution of TFP growth rate across the two models (new model vs translog) we carry on our analysis with the estimated factor elasticitites. In Figure 3 we present the marginal posterior distributions of factor elasticities from the two models (new model vs baseline parametric model). For the Bayesian nonparametric model, the factor elasticities are averaged across all MCMC draws to take into account parameter uncertainty.

Based on the upper and bottom panels of Figure 3 some important differences can be seen. First, three (non-productive labor, energy, materials) out of five factor elasticities of the new model show a relatively low variation taking values around zero within the interval $0.0-0.2$. In contrast, capital services' elasticity (blue line) and productive labor elasticity (orange dotted line) exhibit a different pattern with wider distributions and larger values. Specifically, the former takes values from 0.1 to 0.3 while the latter ranges from 0.5 to 0.65 . A different trend is evident when the baseline parametric model is put into scrutiny. Specifically, all the factor elasticities except for capital services, have a symmetric posterior distribution but with low estimated mean not exceeding 0.3 (non-productive labor elasticity). The latter (green dotted line) is somewhat skewed to the right, suggesting that for most four-digit sectors the factor elasticity shows slight asymmetry to the right. Similar findings hold in the case of capital services' elasticity (blue line), where the relevant marginal posterior density is positively skewed ranging from 0.3 to 0.5 , suggesting that for most manufacturing sectors the impact of factor substitution is moderate. Since the upper and lower panel are in the same scale, it is apparent that factor elasticities differ greatly in the two models. 
Figure 3. Posterior distributions of factor elasticities (new model vs translog)
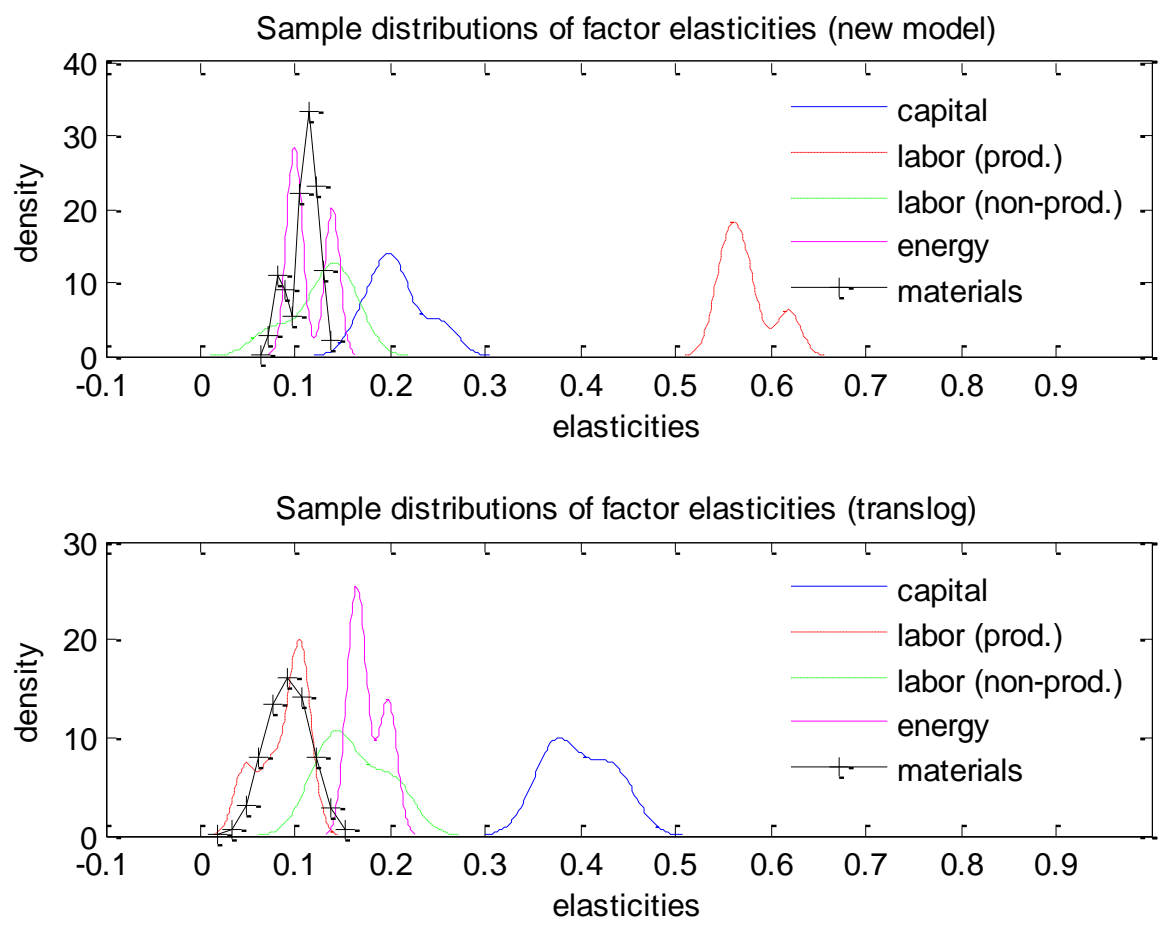

Source: Authors' estimations.

In Figures 4 and 5 we present the posterior mean marginal effects of each of the five factors (along with the time trend) on TFP growth rate provided by the non-parametric model. Marginal effects are computed using numerical derivatives of the non-parametric functional form averaged across MCMC draws (excluding the burn-in phase). In this way, we can draw inferences about the pattern of TFP in the US manufacturing industry over the sample period. 
Figure 4. Marginal effects of factors on TFP growth

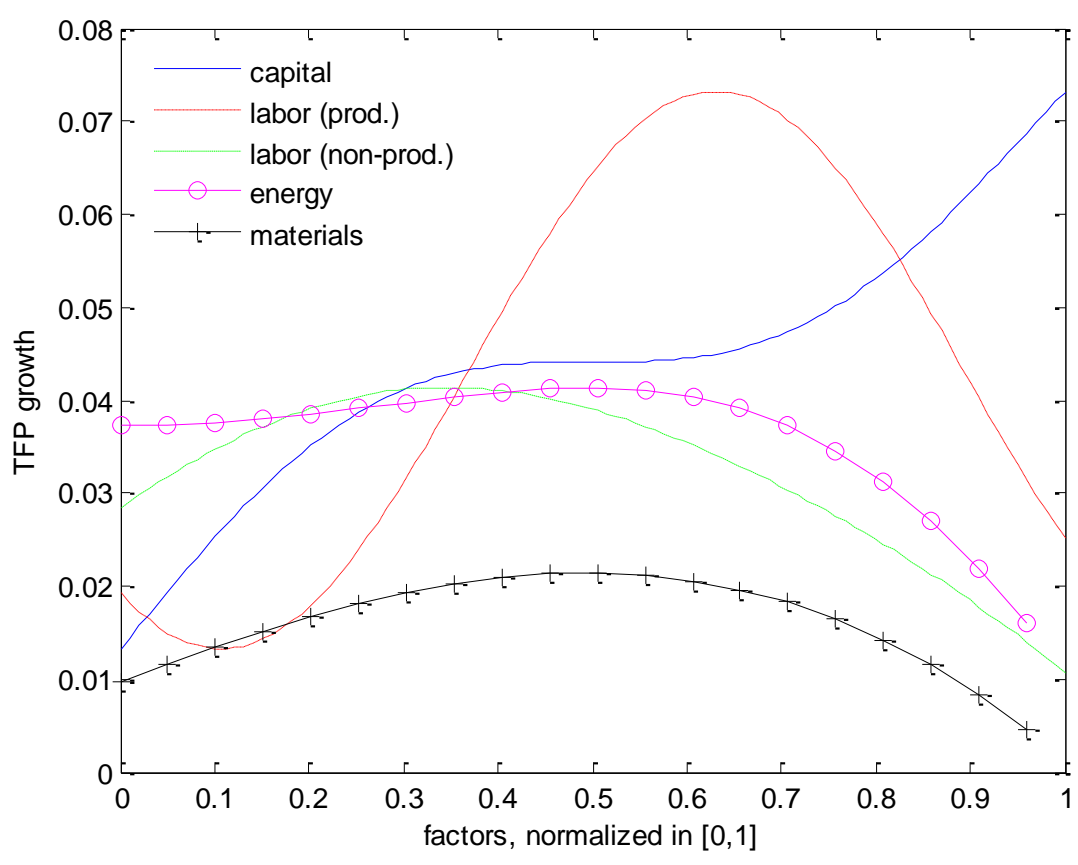

Source: Authors' estimations.

Figure 4 shows the decomposition of TFP growth by factor. As it is evident the marginal effects of the five input factors on TFP growth rate are nonlinear. Nearly all factor marginal effects (except for capital services) show an inverted " $U$-shape" form with a turning point (threshold) equal to the median (0.5) approximately. This means that the marginal effects of the four input factors on TFP growth are nonlinear. In contrast, the marginal effect of capital services on TFP growth rate has an "S-shape" form with two turning points around 0.3 and 0.65 , respectively.

It is noteworthy that the lion's share of TFP growth in US manufacturing sectors is due to productive labor (i.e. white-collar workers) and capital services. The two factors contribute significantly to the decomposition of TFP growth compared with other sources of growth such as materials (energy excluded) and non-productive labor (i.e. blue-collar workers). These findings contradict some of the existing studies (see for example Mamuneas et al., 2007; Sharma et al., 2007; Ketteni et al., 2011, and Cardarelli and Lusinyan, 2015) highlighting that TFP growth mainly stems from technological progress. This could be attributed to various reasons such as the different (parametric) methodologies applied along with the different dataset as well as the fact that all the previous reported studies do not address the impact of market structure on TFP growth rates. 
In Figure 5 we report the MCMC - averaged effect of time on TFP, which is $\mathcal{T}\left(X_{i t}, \tau_{i t}\right)$ as in (4). The marginal effect seems to be cyclical around the median (0.5). More specifically, for the values below the median, the marginal effect of time trend on TFP follows an upward trend until a certain point (nearly 0.4 ) where it switches to an abrupt downward trend. In contrast, for values above the median of the distribution, the marginal effect exhibits a sudden increase in the interval $0.5-0.9$, approximately.

Figure 5. Marginal effect of time trend on TFP growth

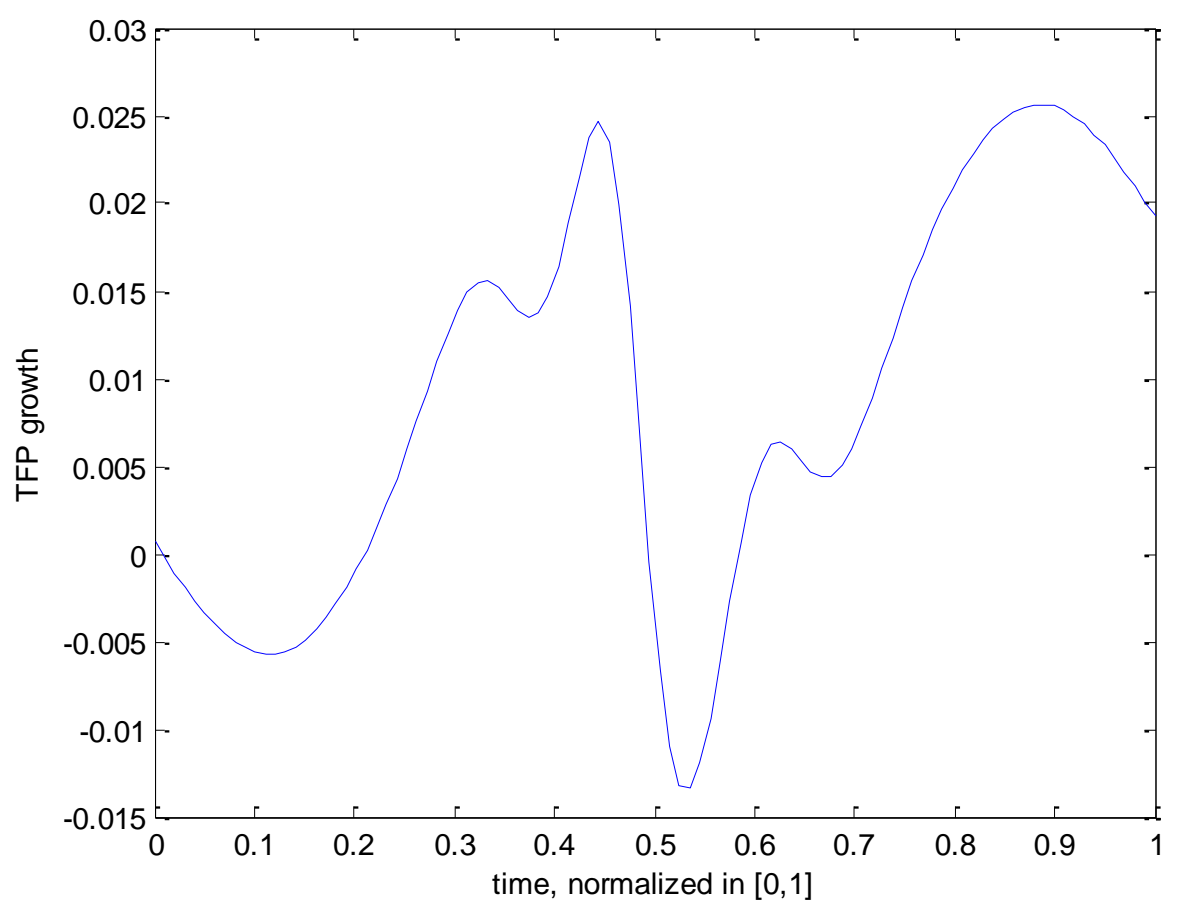

Source: Authors' estimations.

\subsection{Sensitivity analysis}

We conduct a number of sensitivity analyses on the results to examine the robustness of our empirical findings. In particular, we obtain estimates of TFP growth by trimming $1 \%$ of outliers from both edges of the distribution of TFP. In this way, we test for the robustness of the non-parametric empirical findings since local regression may be sensitive to outliers (Delis et al, 2014). Moreover, we include fixed effects and time effects among the regressors in the parametric 
model (translog). The results are not significantly different from those reported in Section 5.1. ${ }^{9}$ In addition to the above, we test the validity of the assumption of time-invariant factor elasticities in our Bayesian context. Finally, we use a set of diagnostic procedures to ensure that we have a nonparametric specification not rejected by the data. The relevant tests show that our nonparametric method (new model) to estimate TFP growth, performs well in terms of these diagnostic tests.

\subsubsection{Time-varying factor elasticities}

We turn attention into possible time-variation in factor elasticities and heterogeneity across industries and / or time. One may argue that a "one size fits all" nonparametric production function is, in fact, wrong as there may be considerable heterogeneity across different industries. To address this concern, we assume that we can classify the data into $G$ groups, where $G$ is unknown. Bayesian analysis can be performed using a simple extension of the MCMC procedure (for details, see Appendix A.1) for a fixed value of $G$. We select the number of groups, $G$, using the marginal likelihood criterion. The marginal likelihood is computed for each $G$ in $\{1,2, \ldots, 7\}$ and the optimal values was $G=5$ (see Table 2). Marginal likelihood ${ }^{10}$ is computed using the DiCiccio et al. (1997) approximation. The different values of marginal likelihood are shown in the following table.

\footnotetext{
${ }^{9}$ Due to space limitations, the results are available upon request.

${ }^{10}$ Also known as Bayes factor, when the prior odds ratio for different values of $G$, is equal to one.
} 
Table 2: Values of marginal likelihood for different values of $G$

\begin{tabular}{|c|c|}
\hline$G$ & marginal likelihood \\
\hline 1 & 1.0000 \\
\hline 2 & 12.717 \\
\hline 3 & 17.332 \\
\hline 4 & 21.330 \\
\hline 5 & $\mathbf{5 3 . 4 4 5}$ \\
\hline 6 & 17.002 \\
\hline 7 & 9.3710 \\
\hline
\end{tabular}

Source: Authors' estimations. The marginal likelihood for $G=1$ is normalized to 1.000 .

The results are shown in Figures 6 and 7. From the posterior means reported in these figures, it turns out that time variation can be safely ignored and, therefore, our analysis based on time-invariant factor elasticities is supported by the data. One could possibly argue that it is feasible to compute input bias from technical change, using the estimation of a translog function either in its primal (production function) or its dual form (cost function). Indeed, Binswanger (1974) and Fuss and McFadden (1978) present the input bias from technical change using the estimation of a translog cost function. However, as mentioned above, we provide sufficient evidence that input elasticities (e.g. capital services, labor productive, labor non-productive, energy, materials) drawn from the decomposition of TFP growth, are not time varying. This means that we do not have factor biases. Therefore, as elasticities are practically constant over time, the Hicks neutrality hypothesis cannot be rejected showing that technical change is disembodied. 
Figure 6. Factor elasticities over time from finite mixture of normals model

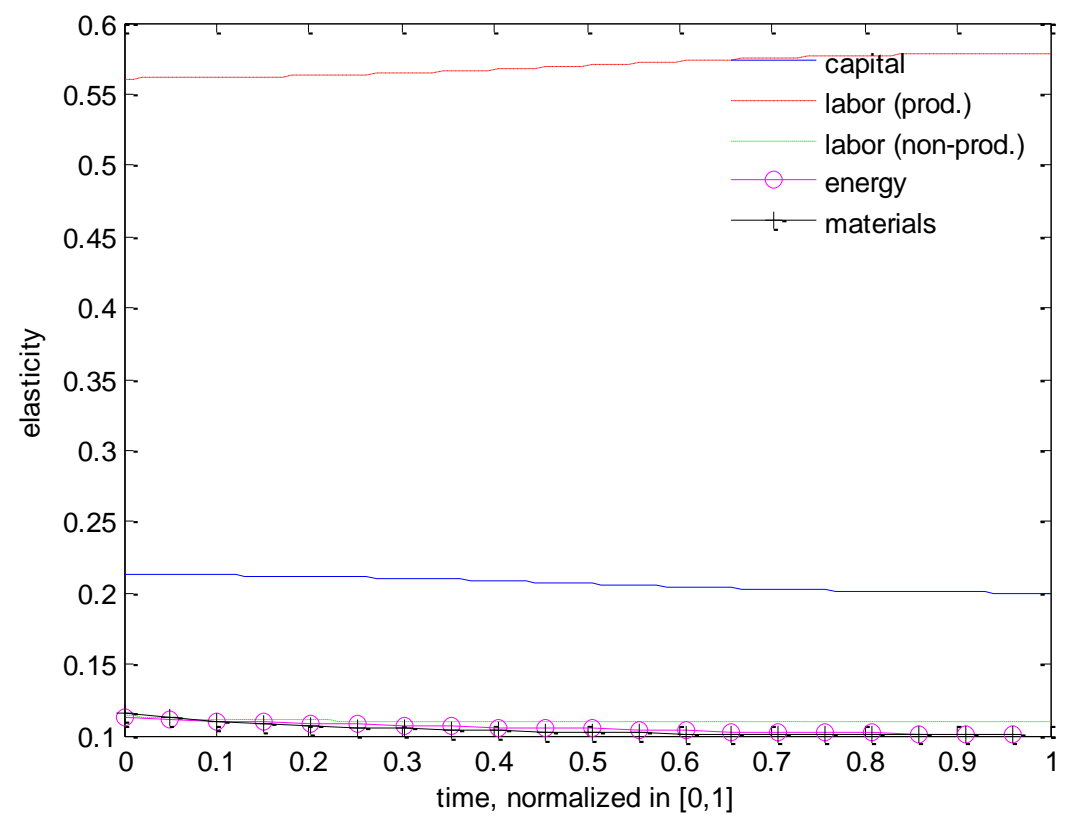

Source: Authors' estimations.

Figure 7. Factor elasticities over time from finite mixture of normal model (individual plots)
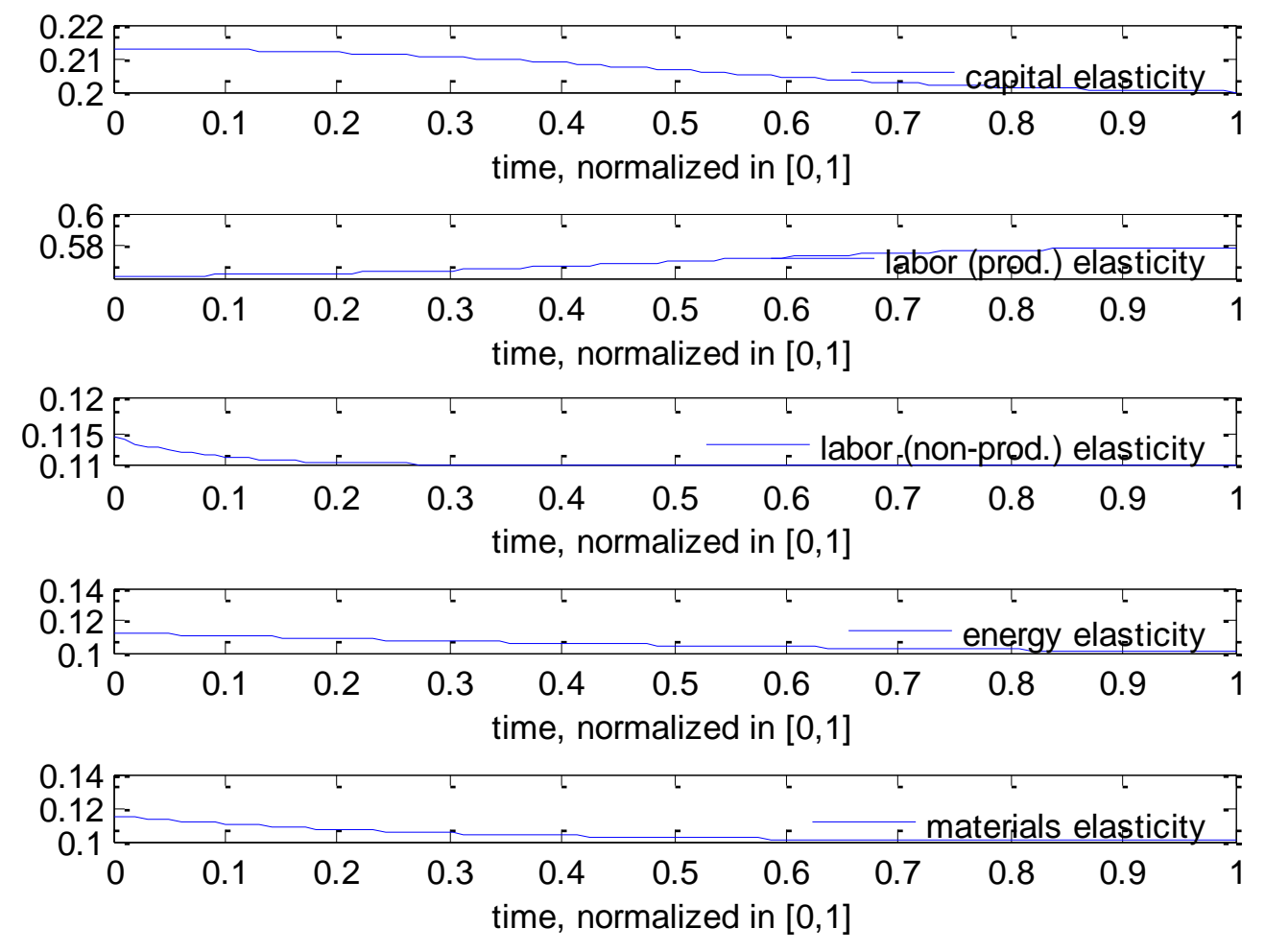

Source: Authors' estimations. 


\subsubsection{Diagnostic procedures for Bayesian analysis}

Given the use of the MCMC, it is essential to assess validity of the instruments used in the procedure and examine autocorrelation of MCMC draws. For these reasons, we use a battery of diagnostic tests to ensure, to an extent that is empirically possible, that we have a specification not rejected by the data. To our knowledge, these procedures are novel in the literature.

Specifically, to test that our instruments are relevant we compute the minimum ${ }^{11} \mathrm{R}^{2}$ between the actual and fitted values, from the nonparametric reduced form, for each MCMC iteration. Therefore, there is an induced posterior distribution of the minimum $\mathrm{R}^{2}$. Figure 8 presents the marginal posterior density of minimum $\mathrm{R}^{2}$ from nonparametric reduced form. As it is evident, the probability density function of the full model (blue line) deliver large values of $\mathrm{R}^{2}$. Additional we present posterior distributions of minimum $\mathrm{R}^{2}$ when lagged growth rates or lagged inputs are not included in the reduced form. In both cases the $\mathrm{R}^{2}$ s drop dramatically indicating that these variables should be present in the reduced form.

Figure 8. Marginal posterior density of R-squared

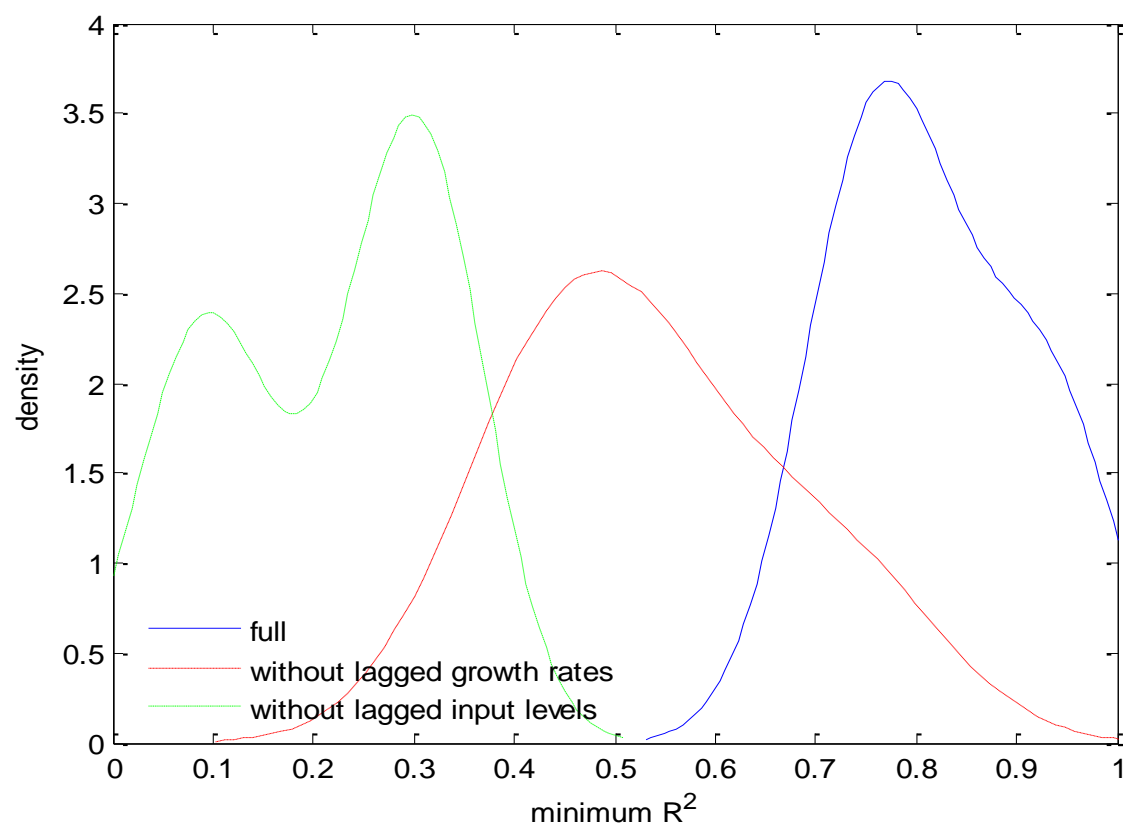

Source: Authors' estimations.

\footnotetext{
${ }^{11}$ The minimum is taken across equations. In what follows, we maintain the assumption that $G=5$.
} 
Similarly to other empirical studies (see for example Tsionas and Izzeldin, 2018), we compute autocorrelation functions (acf) for each parameter to examine autocorrelation of MCMC draws. In Figure 9, we report the maximal values of autocorrelation coefficients estimated at the median $\left(50^{\text {th }}\right.$ percentile) and at the $10^{\text {th }}$ and $90^{\text {th }}$ percentile of $w$ (the particular point at which we consider the local likelihood / posterior) for each lag from 1 to 50 (in absolute values but retaining the sign for plotting). The autocorrelation functions portrayed in Figure 9 shows that the Riemannian MCMC model (new model) performs well after the $10^{\text {th }}$ lag where the acf drops down to 0.2 from 0.8 ( 2 lags). However, its performance is much improved after the $20^{\text {th }}$ lag since the acf are practically zero or take negative values after about lag 30 . These results indicate good mixing properties and thorough exploration of the posterior using our MCMC procedure. The result is not very surprising as the Girolami and Calderhead (2011) MCMC update relies on first and second derivative information from the local log posterior.

Figure 9: Autocorrelation functions

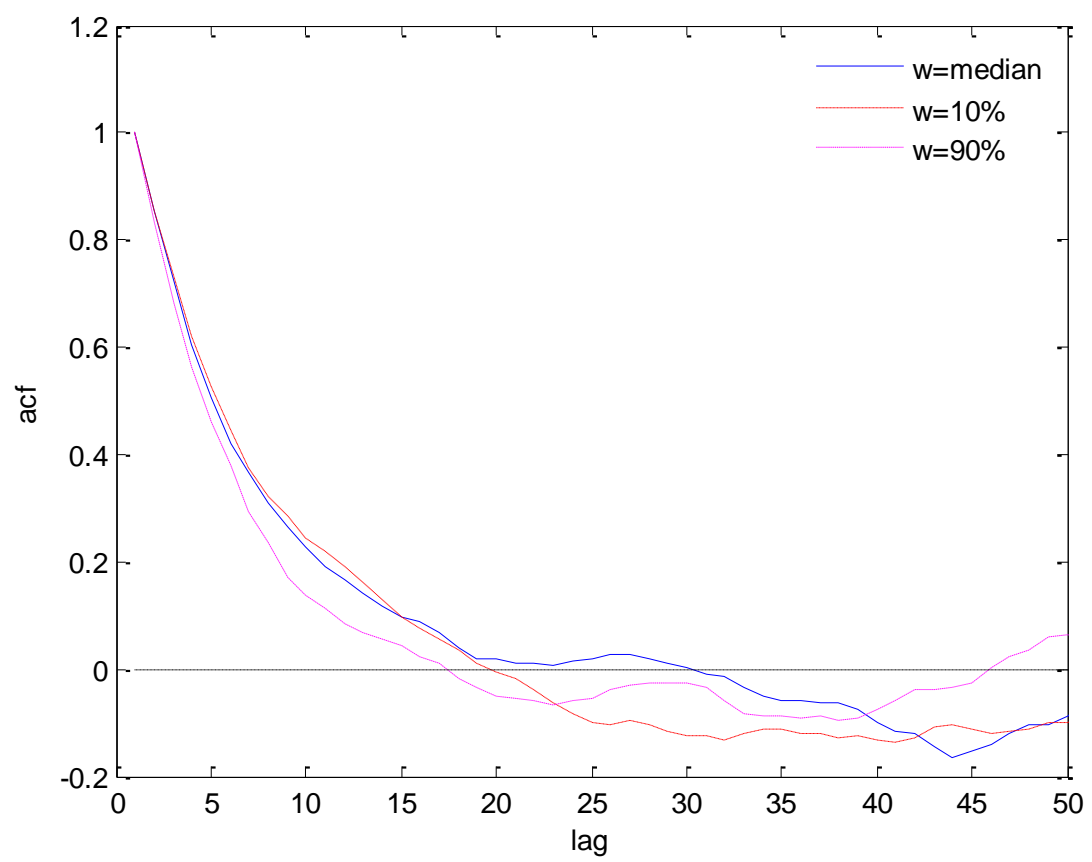

Notes: Corresponds to autocorrelation function (acf) from MCMC when we estimate the functional form at a point $w$ which corresponds to the median, $10 \%$ and $90 \%$ percentiles. At other points the acf was similar. The different percentiles correspond to labor.

Source: Authors' estimations.

Finally, for each MCMC iteration we compute minimum $p$-values of $F$-tests for each residual series accounting for: a) autocorrelation of order 4 , b) heteroscedasticity of type I (where 
squared residuals are regressed on all instruments without squares and / or interactions, c) heteroscedasticity of type II (where squared residuals are regressed on all instruments including squares and interactions, d) a RESET test where residuals are regressed on second, third and fourth powers of the fitted values of the growth equation and the reduced form and finally e) a normality test. In this procedure, there is an induced posterior distribution of $p$-values of $F$-tests. The minimum is taken across equations.

The relevant marginal posterior densities of minimum $p$-values for the five diagnostic tests are presented in Figure 10. The new model does not suffer from autocorrelation or heteroskedasticity since the posterior distributions of $p$-values (blue, orange and green line) are greater than the 0.10 threshold (10\% level of significance in sampling - theory approach) implying that standard specification problems are absent from the specification. ${ }^{12}$

Figure 10. Marginal posterior densities of $p$-values for diagnostic tests

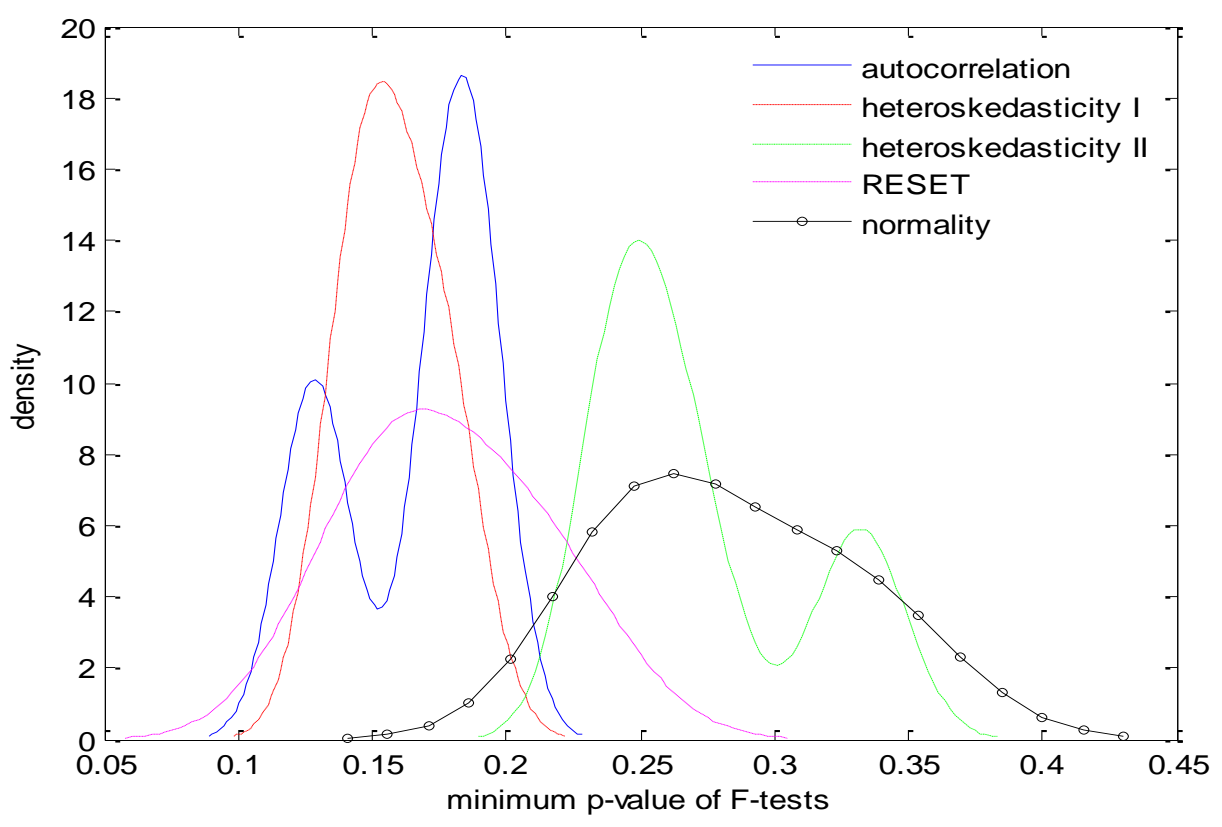

Source: Authors' estimations.

\footnotetext{
${ }^{12}$ No doubt, a "more Bayesian" approach would be to consider Bayes factors or marginal likelihoods relative to the hypothesis that autocorrelation, heteroskedasticity and functional form problems are absent (the "null hypothesis"). Although $p$-values are problematic (to say the least) in a purely Bayesian approach, they can nevertheless be used here to illustrate the extent to which the "null hypothesis" is supported by the data.
} 
According to the shape of the marginal posterior density of RESET - test distribution (purple dotted line), the non-parametric model does not appear to be misspecified so it is an acceptable econometric representation. ${ }^{13}$ If non-linear combinations should have any additional power in explaining the response variable, the model would have been misspecified which does not appear to be the case here. Specifically, we find that the new model passes the Ramsey (1969) test for neglected nonlinearity in the choice of functional form as the sizable probability content of the posterior exceeds the conventional threshold $p$-values of $5 \%$ or $10 \%$. Therefore, we do not have any serious evidence against the suitability of our specification. Finally, the normality minimum $p$-values show that the model's errors are nearly normally distributed since the posterior density places large probability in excess of the $10 \%$ frequentist critical threshold.

\subsubsection{GMM and weak identification testing}

As we analyzed before, we have developed a Bayesian test for valid instruments using the

minimum $\mathrm{R}^{2}$ from the reduced form as in Figure 9. In this section, we illustrate a different identification test which is fully described in Appendix A.2. Specifically, the marginal posterior densities of the $p$-values for both the non-parametric and the translog model are reported in Figure 11. Regarding the translog model we observe that the marginal posterior density of $p$-values has considerable mass in the neighborhood of zero, which means that over-identifying restrictions are rejected. This implies that either the instruments are not proper or the moment conditions are incorrect. In contrast, the new model behaves well implying that over-identifying restrictions cannot be rejected since the relevant $p$-values fall within the interval 0.1-0.6.

\footnotetext{
${ }^{13}$ Most previous studies do not test for the suitability of the functional forms adopted.
} 
Figure 11. GMM marginal posterior densities of $p$-values (New model vs translog)

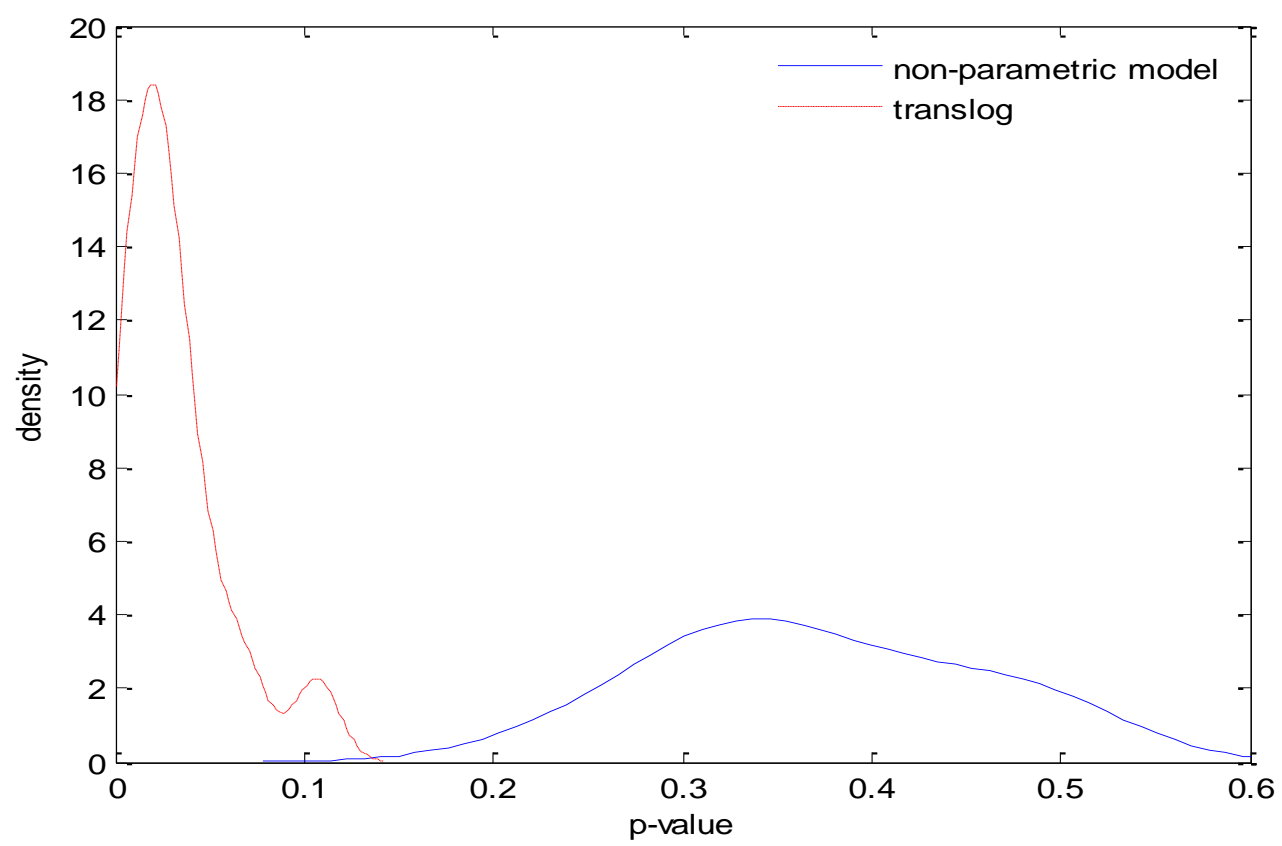

Source: Authors' estimations.

We carry on our sensitivity analysis regarding weak identification testing. According to Stock et al. (2000) tools for investigating identification are rather limited in nonlinear models. For this reason, we develop an alternative test based on three steps. In the first step, we use the twostep GMM criterion in place of the CUE-GMM criterion in (19), evaluated at all MCMC draws and examine whether the marginal posterior distributions of their $p$-values are substantially different. ${ }^{14}$ In the next step, we remove instruments at random and we repeat the same procedure. Specifically, we remove at random $\mathbf{I}$ instruments at a time. We set $\mathbf{I}=1, \ldots, 10$. In turn, we evaluate the GMM criterion across all values of $\mathrm{R}$ and all MCMC draws. In the last step, we remove observations at random and we repeat the same procedure. Specifically, we remove at random $\tau_{\mathrm{o}}$ observations at a time. We set $\tau_{\mathrm{o}}=1, \ldots, 50$. In turn, we evaluate the GMM criterion across all values of $\tau_{\mathrm{o}}$ and all MCMC draws.

Our results are reported in Figure 12 for the non-parametric model (upper panel) and the translog (lower panel). Evidently, the marginal posteriors of $p$-values are very close to the

\footnotetext{
14 The latter is implemented as follows. First, we set $\Lambda=\mathcal{I}$, the identity matrix, at the MCMC draw. Second, we take one iteration of the Gauss-Newton method away from the draw, evaluate $\Lambda$ at the new iterate as in (19) and third, we re-compute the GMM criterion.
} 
original model but this is not the case for the translog model. This finding suggests weak identification problems and / or other misspecifications errors in the parametric model.

Therefore, the new model for the estimation of TFP growth represents a significant improvement over conventional parametric estimation methods (translog). The same is also true relative to the GL and NQ functional forms. The diagnostic tests presented are quite informative in that inferences based on the nonparametric model can be carried out with some confidence. This means that if one researcher or market player does not have information on factor prices and needs factor elasticity estimates to calculate TFP growth, then the estimates from the new method are likely to be more reliable than conventional parametric functional forms. Of course, further validation in other data sets is required before this general issue is settled.

Figure 12. Marginal posteriors of $p$-values (New model vs translog)
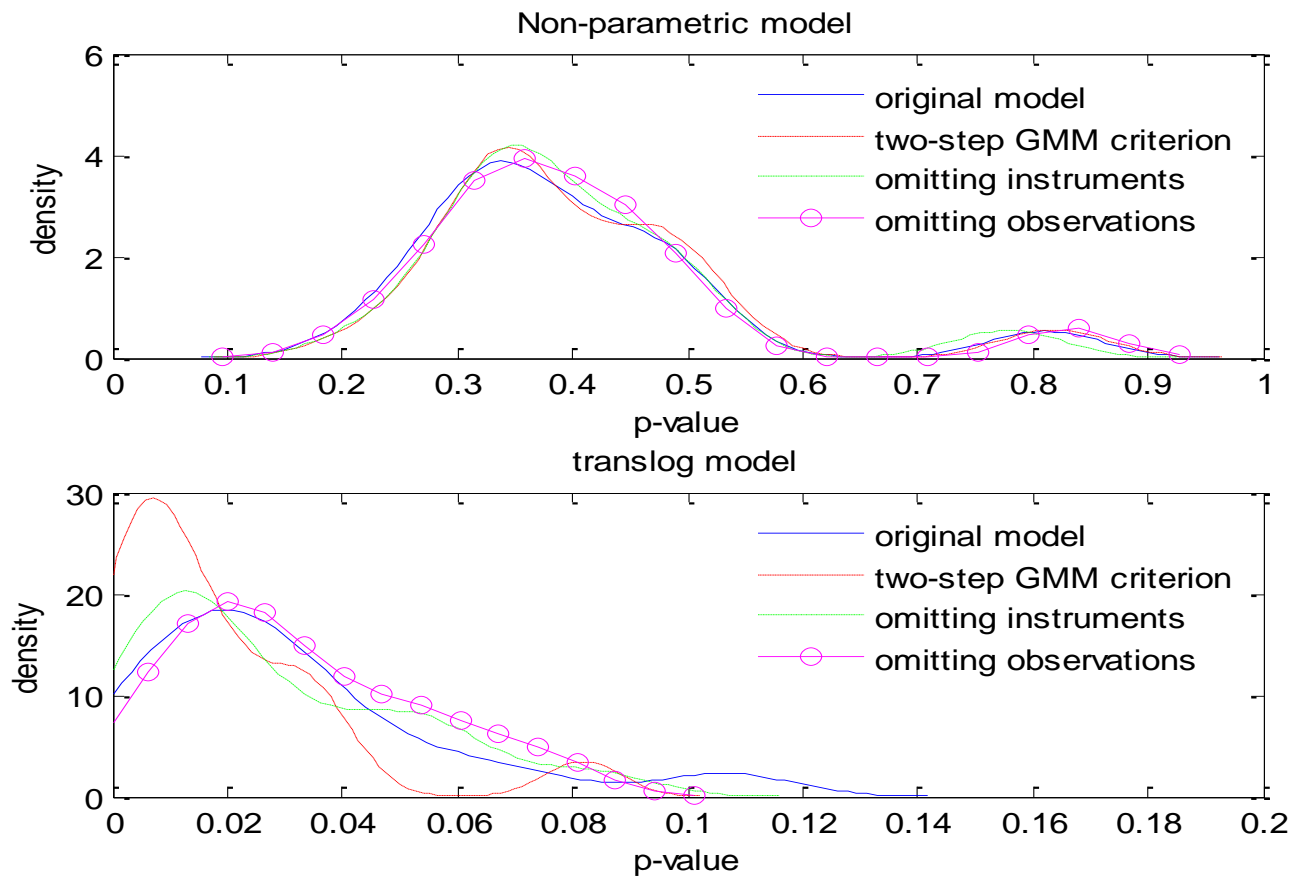

Source: Authors' estimations. 


\subsection{Robustness checks ${ }^{15}$}

In this subsection, we perform several checks to examine the robustness of our results. Specifically, we experiment with other parametric functional forms such as the Generalized Leontief (GL) and Normalized Quadratic (NQ) along with the translog production function to further testing the validity of the TFP growth rates estimated by the nonparametric model.

\subsubsection{The GL and NQ parametric models}

Since all second-order specifications such as the translog or the CES cost function can be viewed as approximations to an arbitrary production function (see Fuss, et al, 1978), we first rely on the GL specification, which acknowledges that there may be limited substitution among inputs but considerable substitution among materials in the production process (Diewert, 1971). Specifically, the non-homothetic Leontief production function suggested by Lau and Tamura (1972) is the most general production function characterized by zero elasticities of substitution between all pairs of inputs allowing at the same time differential returns-to-scale and technical progress to inputs (Lau and Tamura, 1972; Genius et al, 2012). In such a case input demand functions may differ across factors of production. The GL production function (Diewert, 1971) is given by what Diewert called the "generalized linear" form which is the equivalent of his 3.1 in 4.2 and is given by:

$$
Y=a_{0}+\sum_{k=1}^{K} a_{k} X_{k}^{1 / 2}+\sum_{k=1}^{K} \sum_{k^{\prime}=1}^{K} a_{k k^{\prime}} X_{k}^{1 / 2} X_{k^{\prime}}^{1 / 2}
$$

We supplement our analysis with the NQ functional form (Lau, 1978) which is given by the following equation:

$$
Y=a_{0}+\sum_{k=1}^{K} a_{k} X_{k}+\sum_{k=1}^{K} \sum_{k^{\prime}=1}^{K} a_{k k^{\prime}} X_{k} X_{k^{\prime}}
$$

We do not impose normalization to have homogeneity of degree one in inputs (viz. constant returns to scale). Therefore, this is a quadratic production function in our context.

Additionally, both GL and NQ production functions are estimated using our reduced form in (9) to avoid endogeneity problems so that the comparison with the new model is fair. In the case of cost functions, we divide all prices by the first input price to impose homogeneity of

${ }^{15}$ We thank an anonymous reviewer for suggesting to compare our results with the GL and NQ specifications. 
degree one. Moreover, we impose monotonicity at 10 random points in the support. Matrices $\left[a_{k k^{\prime}}\right]$ are symmetric and negative semi-definite (the latter constraint is imposed by exploiting the Cholesky representation of $\left.\left[a_{k k^{\prime}}\right]\right)$.

\subsubsection{Empirical results}

In Figure 13, we present the median TFP growth rates drawn from the new model (nonparametric MCMC) and the other three parametric models (translog, GL and NQ) along with the actual data for comparison purposes. As it is evident, the significant variation between the parametric models and the NBER data still persists even in the case of GL and NQ, while on the other hand the new model illustrates almost a perfect fit to the actual data. This suggests that the results are robust. More related findings are presented in the Figures provided in Appendix A.3 (see Figures A.1-A.3).

Figure 13. Median TFP growth rates across industries over time (New model vs parametric models)

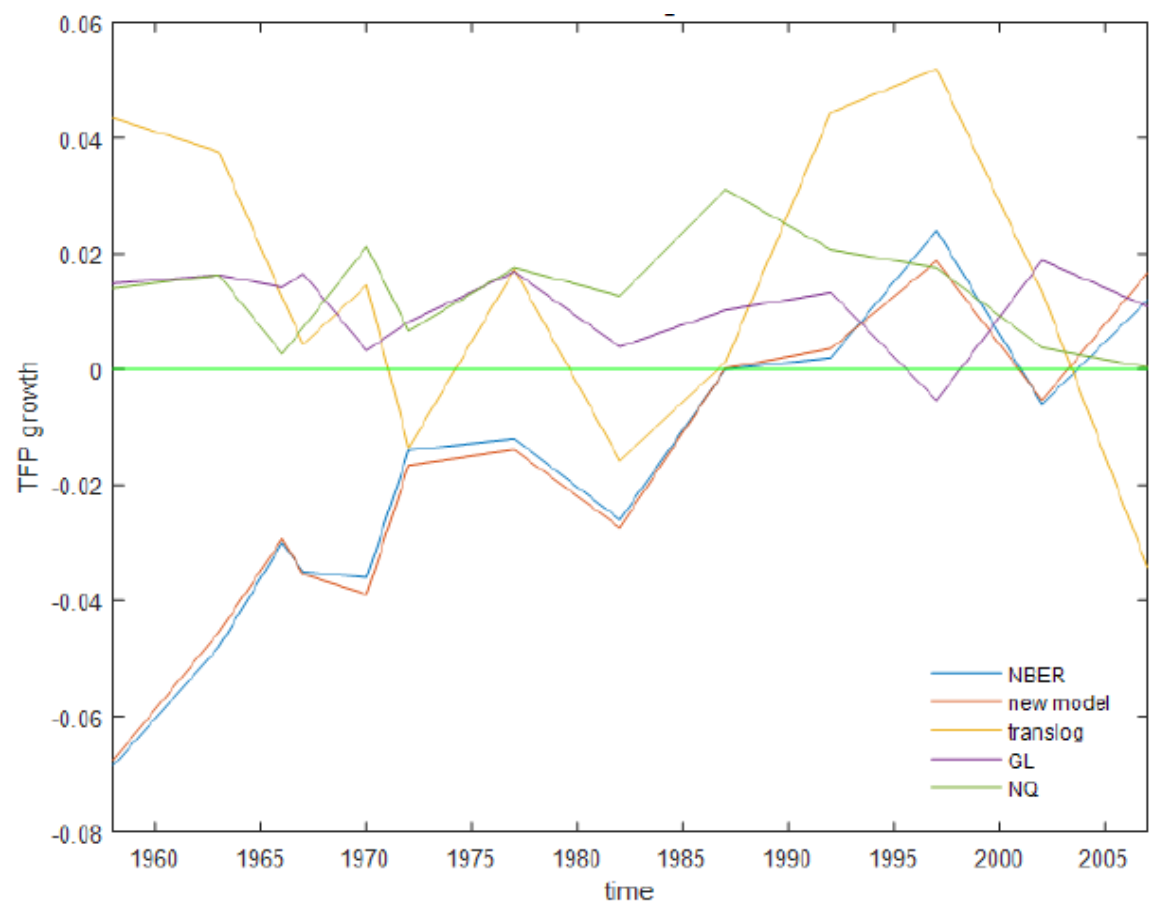

Source: Authors' estimations.

We carry on our analysis with the presentation of marginal posterior densities of the $p$-values for diagnostic tests in all functional forms (non-parametric vs parametric models) as illustrated in Figure 14. We observe that, overall, the new model behaves well since it does not suffer from 
autocorrelation or heteroskedasticity and the normality test indicates that the model's errors are likely to follow normal distributions. Moreover, based on the RESET test the nonparametric model does not appear to be misspecified. However, the same findings do not apply for GL and NQ.

Figure 14. Marginal posterior densities of p-values for diagnostic checks (New model vs parametric models)
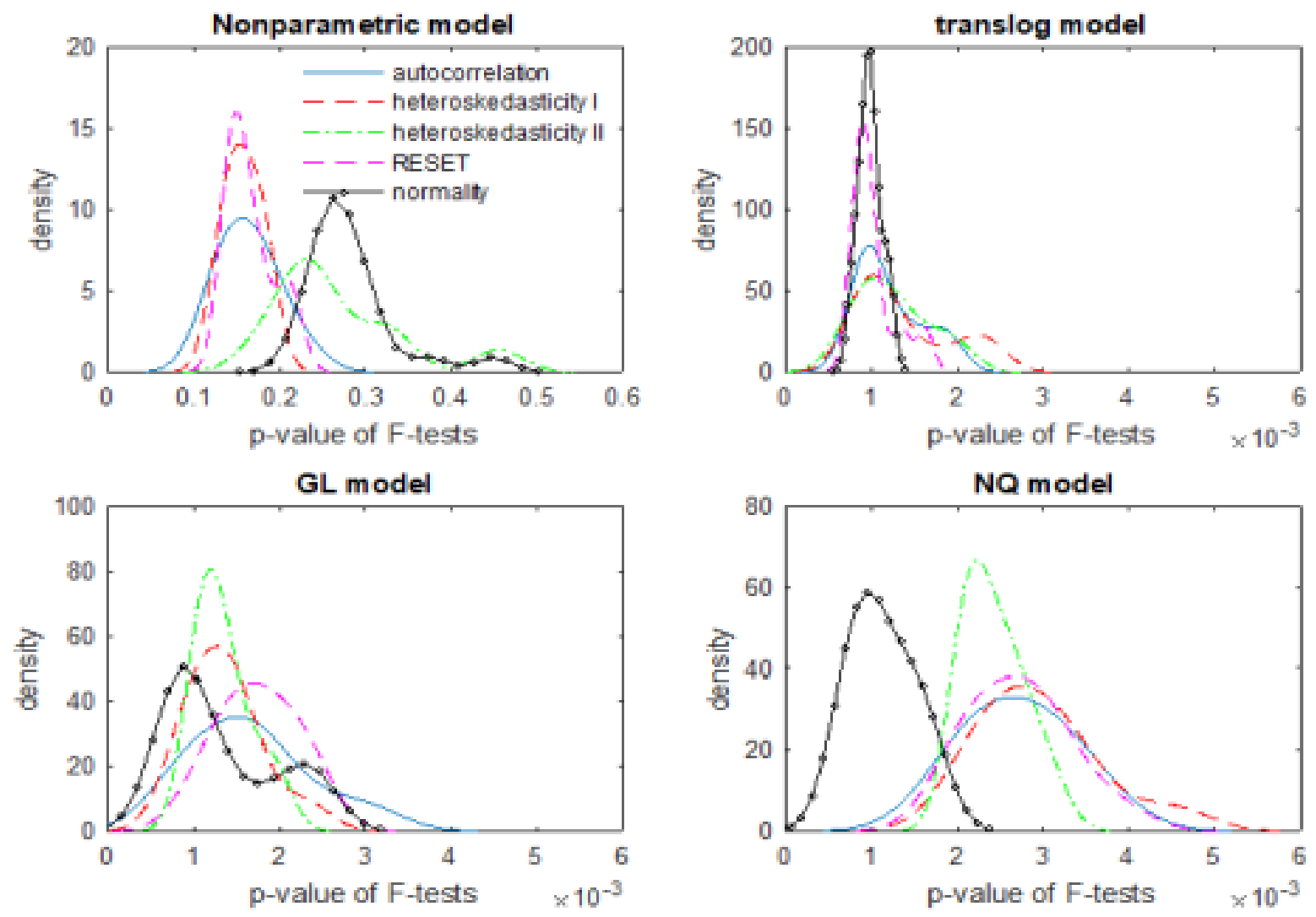

Source: Authors' estimations.

The aforementioned findings are fully confirmed in terms of weak identification testing (see Figure 15). The marginal posteriors of $p$-values provide support in favor of the presence of a weak identification problem and the existence of serious misspecifications errors which are evident in all three parametric functional forms. On the other hand, the nonparametric model seems to behave much better in terms of specification. 
Figure 15. Marginal posteriors of p-values (New model vs parametric models)
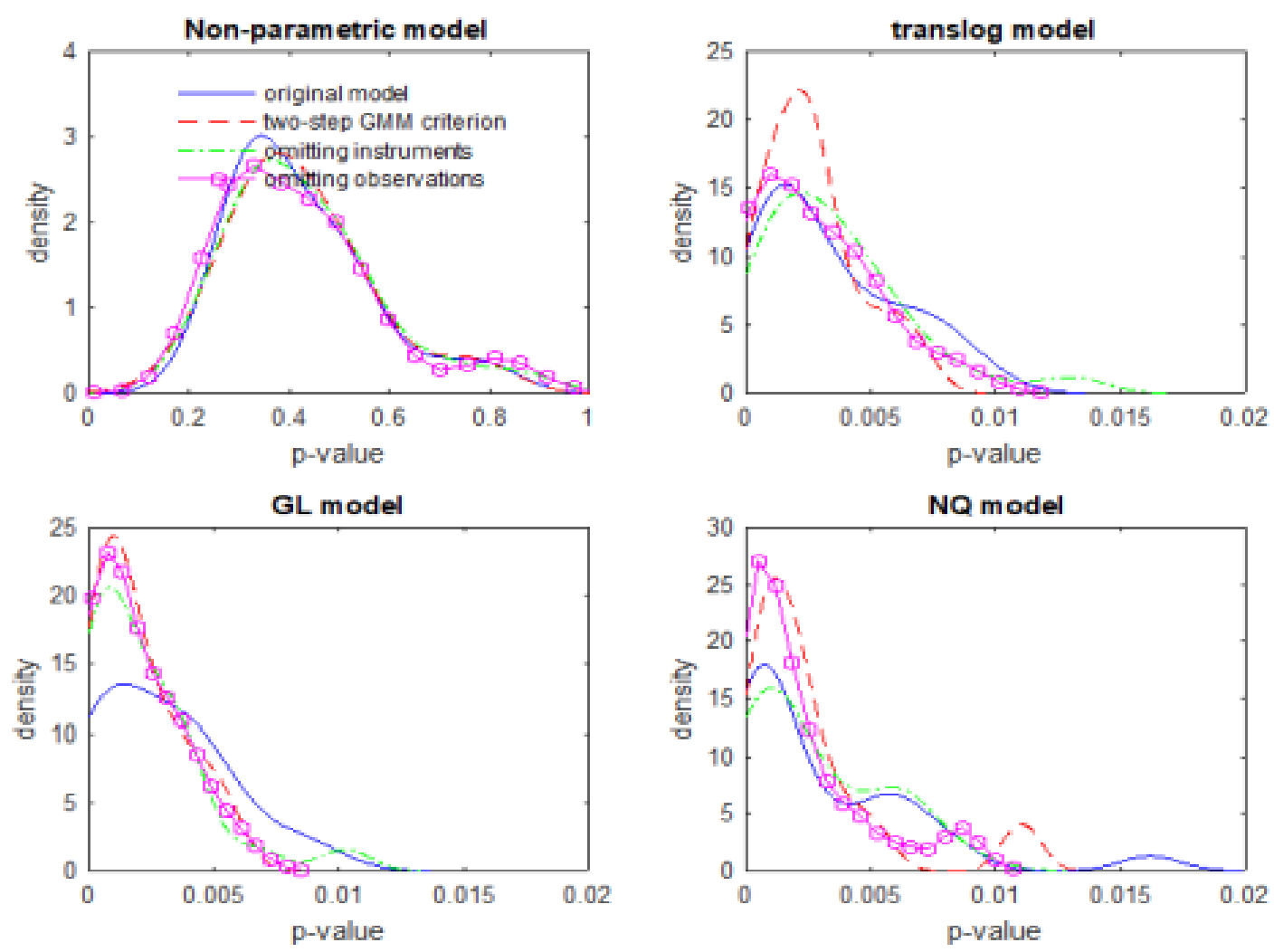

Source: Authors' estimations.

Finally, we conclude our robustness checks with the presentation of factor elasticities estimated from all empirical models (see Figure 16). Factor elasticities differ greatly between the new model and the other three parametric functional forms, showing that model choice is quite important and factor elasticities are sensitive to this choice. 
Figure 16. Sample distributions of factor elasticities (New model vs parametric models)
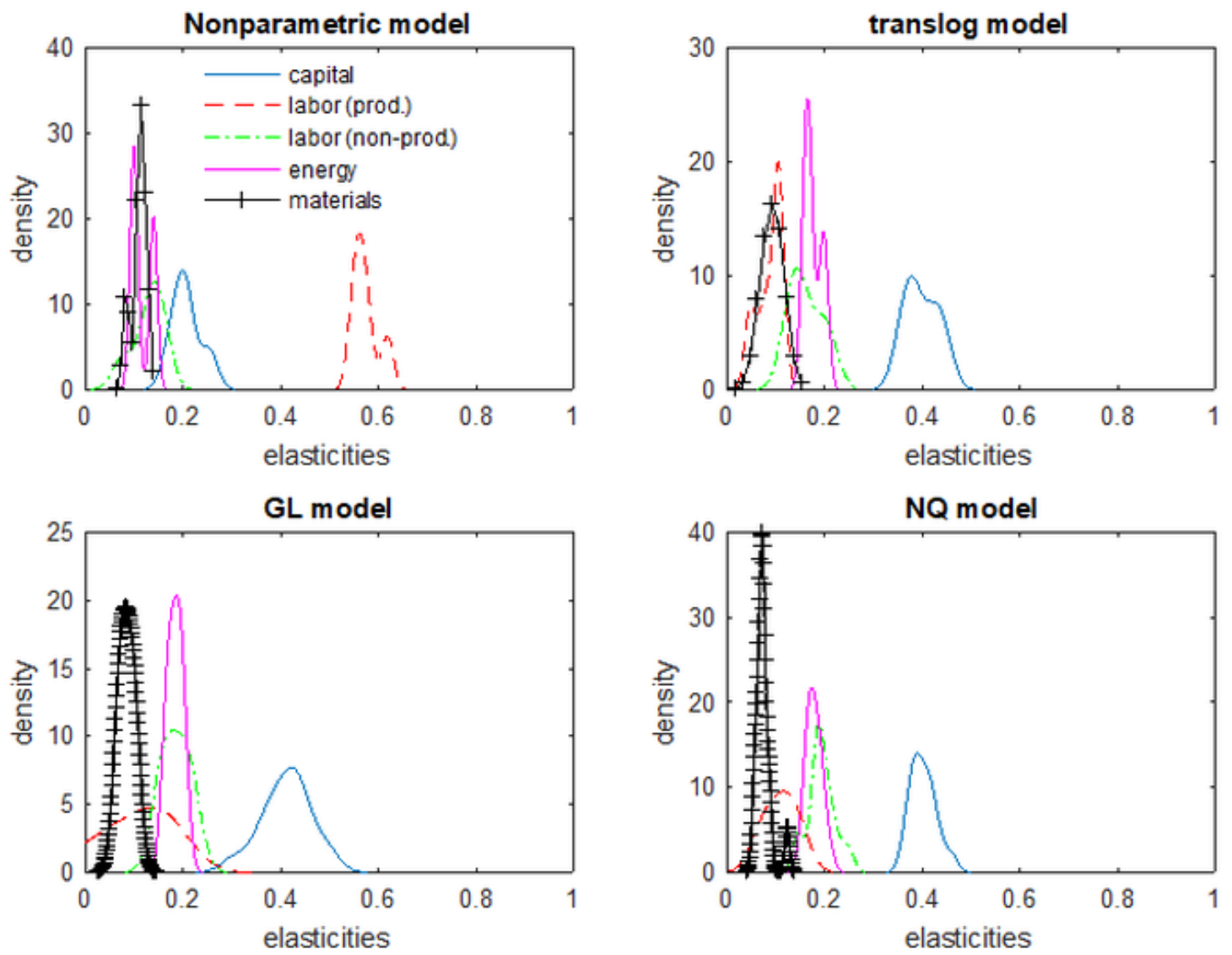

Source: Authors' estimations.

\subsection{Policy implications}

To draw sharp policy implications, we derive results for key functions of interest without reestimating the nonparametric model but by examining results based on splitting the whole sample into five distinct sub-samples including capital $(\mathrm{K} / \mathrm{Y})$, productive and non-productive labor $(\mathrm{L} / \mathrm{Y})$, energy $(\mathrm{E} / \mathrm{Y})$ and material $(\mathrm{M} / \mathrm{Y})$ intensive sectors. For this reason, we have delineated the sectors' competitive conditions as 'concentrated' or less competitive and "less concentrated" or competitive. ${ }^{16}$

\footnotetext{
${ }^{16}$ This was performed by simple splitting the sample of manufacturing industries bellow (competitive) and above the mean (concentrated) of the CR4 .
} 
In Figure 17, we show the effect of K/Y (also productive and non-productive L/Y and CR4) on TFP growth by percentile of these variables. For example the effect of K/Y (which is capital-output ratio) is negative bellow the median (approximately up to the $40 \%$ quantile), and increases becomes positive at, approximately, above the $60 \%$ quantile. The effect is S-shaped like the effect of productive labor $\mathrm{L} / \mathrm{Y}$, while the non-productive labor $\mathrm{L} / \mathrm{Y}$ has a $\mathrm{U}$-shape having a negative effect on TFP growth up to, the $60 \%$ quantile approximately. The effect of CR4 on TFP growth is negative but not statistically important below the $20 \%$ quantile, approximately, and increases at a decreasing rate (inverted $U$-shape) reaching a maximum of $2 \times 10^{-3}$. In contrast, the quantitative effects of $\mathrm{K} / \mathrm{Y}$, productive $\mathrm{L} / \mathrm{Y}$ and non-productive $\mathrm{L} / \mathrm{Y}$ are approximately $1 \%, 1 \%$ and $0.02 \%$ around the median but, roughly, $2 \%$ near the $90 \%$ quantiles, showing that their effect on TFP growth is quantitatively important.

Figure 17. Posterior mean marginal effects of factor ratios to TFP growth by quantile
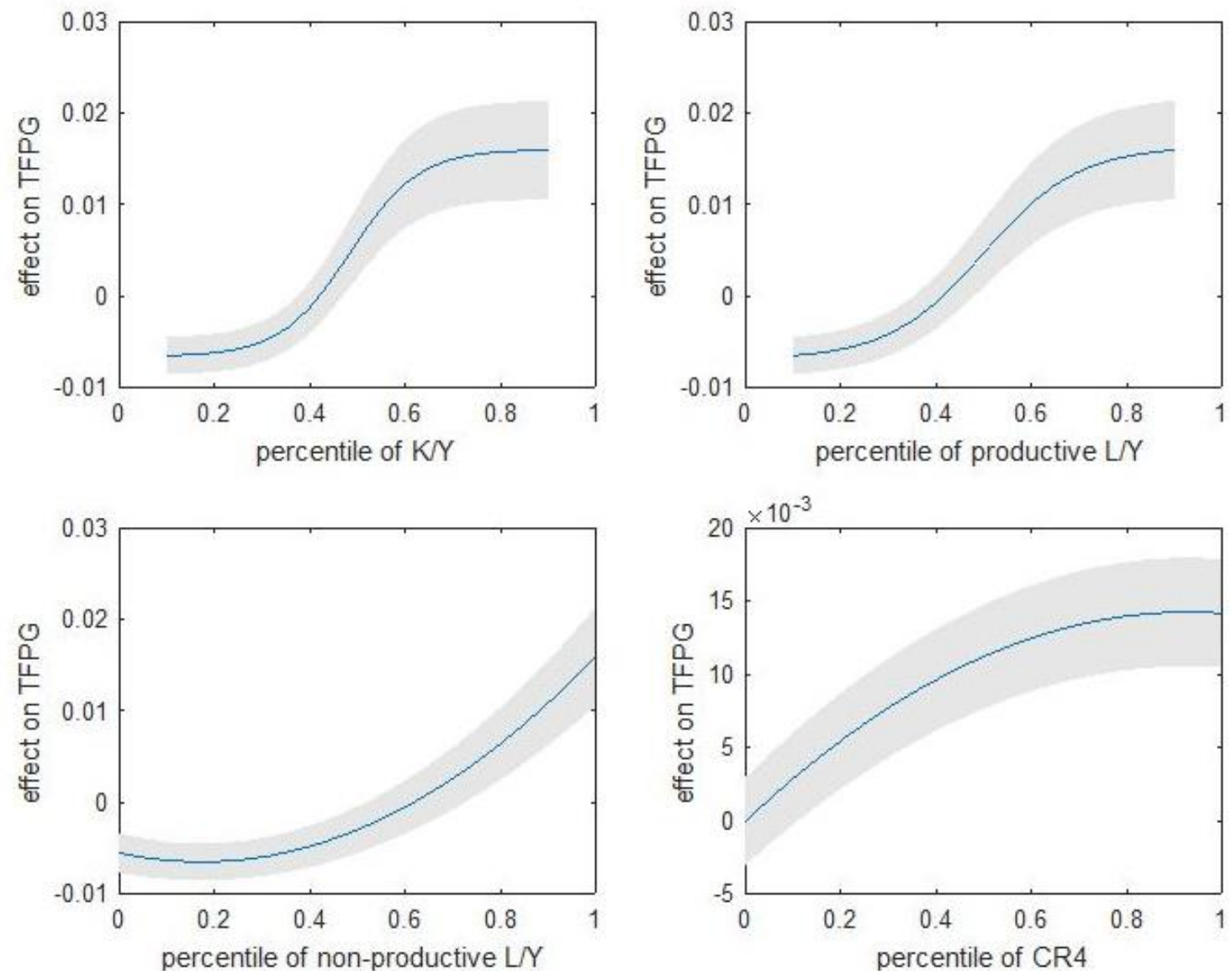

Notes: The grey area corresponds to confidence bands.

Source: Authors' estimations. 
In Figure 18 we focus exclusively on marginal effects of CR4 on TFP growth by quantiles of all different factor-output ratios. As it is evident, CR4 contributes differently to TFP growth across the distribution of inputs. All the effects are, however, close to slightly above zero near the median and reach a maximum of, approximately, a factor of $10^{-3}$. The marginal effects are nonlinear as a function of factor output quantiles, and statistically important. For example, the marginal effect of CR4 is increasing as we move to higher quantiles of $\mathrm{K} / \mathrm{Y}$, non-productive $\mathrm{L} / \mathrm{Y}$, $\mathrm{E} / \mathrm{Y}$ and $\mathrm{M} / \mathrm{Y}$. So for these inputs the CR4 effect on TFP is larger for more factor-intensive industries. Productive $\mathrm{L} / \mathrm{Y}$ is an exception as there is a maximum marginal effect of CR4 around the $70 \%$ quantile of productive $\mathrm{L} / \mathrm{Y}$ and then decreases as we move to the right of the distribution of this input.

Figure 18. Posterior mean marginal effects of CR4 on TFP growth by quantile of factor ratios to output.
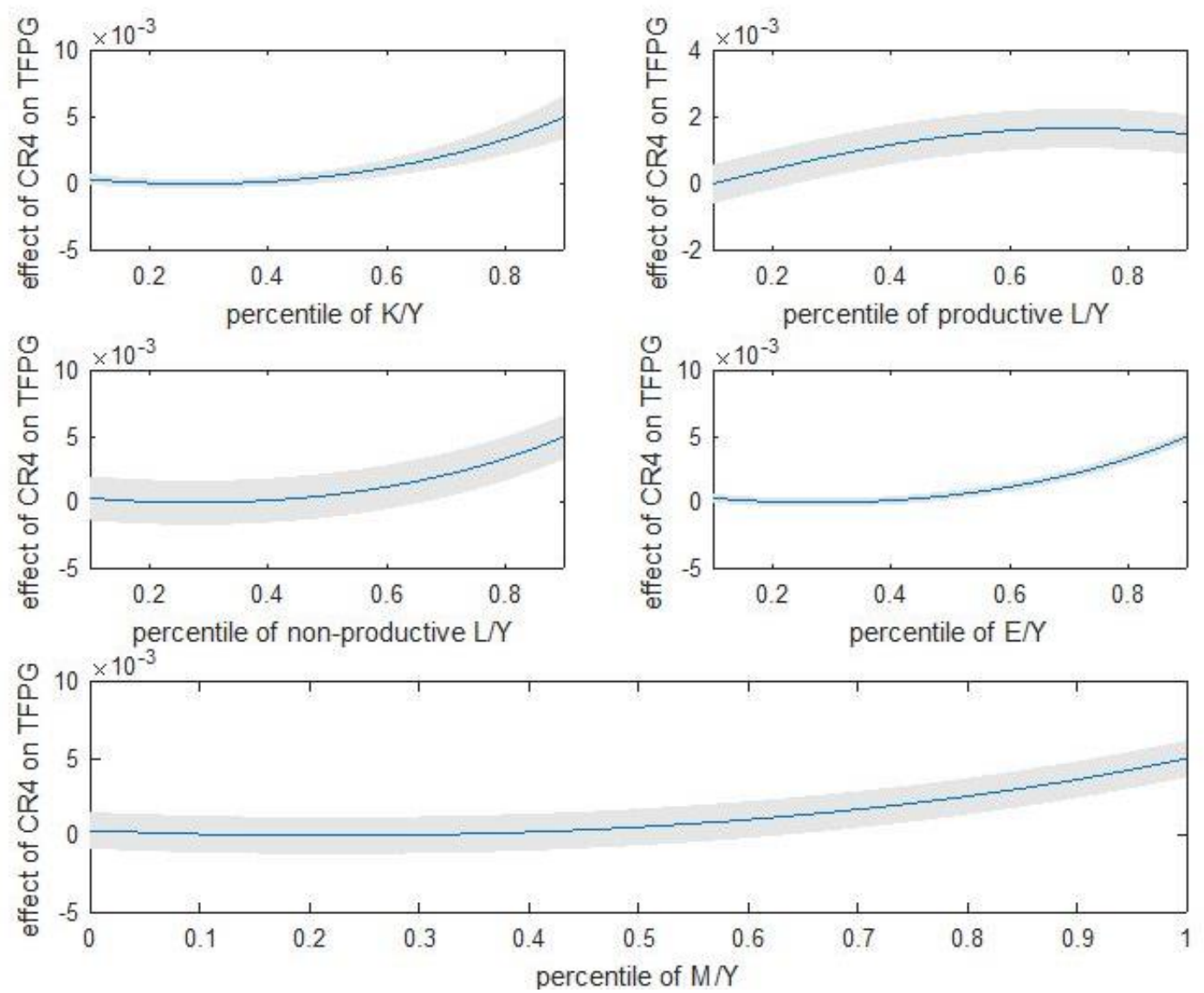

Notes: The grey area corresponds to confidence bands.

Source: Authors' estimations. 
Moreover, it is worth emphasizing that industries with very large $\mathrm{K} / \mathrm{Y}$ (high capitalization relative to output) seem to contribute, nearly, 0.004 to TFP growth (i.e nearly 0.4 percentage points to TFP growth). Productive L/Y contributes, almost, $0.2 \%$, non-productive $\mathrm{L} / \mathrm{Y} 0.5 \%$, and the same is true for high $\mathrm{E} / \mathrm{Y}$ and high $\mathrm{M} / \mathrm{Y}$ industries. Therefore, these effects of CR4, across the distribution of factor-output ratios are statistically and economically important. Along with the evidence in Figure 17, industries near the upper end of the factor-output distribution contribute almost two percentage points to TFP growth. Industries at the upper end of the CR4 distribution contribute much less (approximately 0.15 percentage points). Therefore, it seems that factor intensity (for capital and the two types of labor) is quite important for TFP growth. CR4 is also important and contributes almost half a percentage point to TFP growth, nearly across the entire distribution of factor-output ratios.

From Figure 17 it is evident that both $\mathrm{K} / \mathrm{Y}$ and the two types of $\mathrm{L} / \mathrm{Y}$ contribute significantly to TFP growth, for those industries that exceed the median of the distribution of factor-output ratios. A "Schumpeterian view" is confirmed in that higher concentration implies more TFP growth (lower right panel of Fig. 17) but this effect is much lower compared to factoroutput effects on TFP growth (e.g. 0.1 percentage point versus two percentage points for factoroutput ratios). So, although a "Schumpeterian view" is correct its quantitative importance, although significant, is lesser compared to the role of inputs in TFP growth. This evidence is not, of course, inconsistent with our previous finding that TFP growth is, practically, disembodied. The reason is that this statement refers to the intertemporal role of factors in technical change, while our analysis here focuses on movements along the distribution of factor-output ratios.

From the policy point of view, our empirical results imply that higher concentration is not really harmful in terms of TFP growth, and its effect can be taken as approximately constant across the distribution of factor-output ratios. As we mentioned, near the upper end of the distribution of factor-output ratios is, nearly, half percentage points (Figure 18). From the same figure, we see that at the bottom end of the distribution the effect of higher CR4 on TFP growth is not important and, in most cases, "bottom end", practically means less than the median. From Figure 17 it is evident that factor ratios have an important effect on TFP growth but this effect is positive only above the median of the distribution. So a combination of higher CR4 as well as higher factor usage relative to output is quite important for firms to achieve higher levels of TFP growth. 
Based on the above, we argue that policy makers and practitioners have to stimulate investment activity in highly concentrated value-added sectors (for example oil drilling and refining, automobile industry, iron and steel industry, etc) to enhance their productivity levels. Moreover, the empirical findings of this study allow us to conclude that the positive effects on TFP growth of the more four factor-output intensive sectors (K/Y, non-productive $\mathrm{L} / \mathrm{Y}, \mathrm{E} / \mathrm{Y}$ and $\mathrm{M} / \mathrm{Y}$ ) can be achieved through increased market concentration.

In such a case, we argue that oligopolies might be a proper type of market structure in spreading TFP growth among the manufacturing sectors. This incurs important policy implications toward the increased productivity of the US manufacturing sector. For instance, government officials should facilitate the process of technology adoption through the innovation channel (i.e. R\&D activity, patents and licenses, etc) by fine-tuning institutional and regulatory framework so as to boost productivity spillovers along with the encouragement of higher factor usage (capital, productive labor, energy, material) relative to output.

On the other hand, the empirical findings postulate that in less four-factor intensive industries (e.g. bakery products, beverages, apparels and other finished products, etc), the effect of CR4 on TFP growth is almost negligible. In such a case, the government should pursue policies including inter alia human capital programs, energy saving strategies, product and raw material innovation, that facilitate investment in the specific production inputs (capital, nonproductive labor, energy and raw materials) to boost productivity.

\section{Conclusions and future research}

This paper revisits the issue of the estimation and decomposition of TFP growth without when input prices are unavailable and shows how to derive robust estimates using a novel Bayesian local likelihood approach. To perform the computations, we use techniques organized around Riemannian Manifold Hamiltonian MCMC.

Our sample is an unbalanced panel of four-digit U.S manufacturing sectors over 1958 to 2007. The advantage of our method over estimating parametrically a production function can be mostly attributed to the following. First and foremost, we have a generic decomposition of TFP growth which does not require functional form specification of a production function. In this way we avoid the imposition of specific functional form (translog, Cobb-Douglas, CES, etc.) Second, but equally important, we effectively deal with the common problem of the unavailability of input prices prevailing in the TFP literature. Third, we address input endogeneity by specifying a non- 
parametric reduced form for the endogenous input variables. Fourth, all specifications are scrutinized for various misspecification errors using extensive diagnostic testing.

The empirical findings suggest that the marginal effects of the five factors on TFP growth rate are nonlinear. Specifically, the marginal effect of all inputs, except capital services, on TFP growth exhibit an upward (downward) trend for the values bellow (above) the median justifying an inverted " $U$-shaped" curve. The marginal effect of capital has an "S-shape" form with two turning points around 0.3 and 0.65 relative to the median.

We compare and contrast the estimates from the proposed new method with a set of conventional parametric methods (i.e. flexible translog model, Generalized Leontief and Normalized Quadratic functional forms) estimated by applying GMM to tackle input endogeneity problems. In order to check for the validity of our findings we propose several diagnostic tests for correct specification of the new model. We show that an analysis based on parametric methods can lead to TFP growth estimates that are considerably different among them and relative to the nonparametric model. In addition, the nonparametric model passes a battery of diagnostic tests (normality, functional form, absence of autocorrelation and heteroscedasticity, weak identification, and weak instruments) making it suitable for reliable policy making, at least in our data set. We argue that these findings call for a reconsideration of the literature that relies on TFP growth rate estimates with parametric assumptions. This is of special interest to economists and practitioners as it involves identification of industry conduct in the context of the new empirical industrial organization framework. Moreover, we argue that disentangling the drivers of TFP growth is not only important from an economic but also from a business perspective. Specifically, their identification allows a better and more coherent monitoring of the manufacturing sector, which may guide policy makers, regulators and government officials in their decisions.

Finally, our empirical findings lend support to the argument that higher concentration in more factor-output intensive sectors (i.e. capital, non-productive labor, energy, material sectors) induces firms to innovate and thus stimulate TFP growth confirming the "Schumpeterian view". This might be attributed to the size the firms, since larger firms which are mainly active on concentrated (oligopolistic) sectors are more prone to innovate and thus generate TFP growth due to their financial performance (e.g. increased liquidity, equity, borrowed funding, better access to finance, etc.) compared to smaller and medium sized ones ("scale effect"). However, if we want to have a clear picture on this, we must balance these benefits (i.e. innovation activity, TFP growth) against the negative effects generated by the existence of significant market power (e.g. 
abuse of dominant position, explicit or tacit collusion, etc.) in highly concentrated sectors. This assessment falls outside the scope of this paper and could be left open for future research.

\section{Acknowledgements}

We wish to thank the Editor (R. Teunter) and two anonymous reviewers for their constructive comments. We are grateful to Thanassis Stengos, Emmanuel Mamatzakis, and Nickolaos Tzeremes for comments and suggestions on an earlier version of this paper. The usual disclaimer applies. 


\section{References}

Acemoglu, D. (2009). Introduction to Modern Economic Growth. Princeton and Oxford, MIT Press.

Ackerberg, D., Caves, K., Frazer, G., (2015). Identification properties of recent production function estimators. Econometrica 83 (6), 2411-2451.

Amiti, M. and Konings, J. (2007) Trade liberalization, intermediate inputs, and productivity: evidence from Indonesia. American Economic Review 97: 1611-1638.

Ang, F., and Kerstens, P.J. (2017) Decomposing the Luenberger-Hicks-Moorsteen Total Factor Productivity indicator: An application to U.S. agriculture. European Journal of Operational Research 260(1): 359-375

Atkinson, S.E., Cornwell, C., and Honerkamp. O. (2003) Measuring and Decomposing

Productivity Change. Journal of Business \& Economic Statistics, 21:2, 284-294,

Bartelsman, E.J., and Gray, W. (1996). The NBER Manufacturing Productivity Database. NBER Technical Working Papers 0205, National Bureau of Economic Research.

Bartelsman, E.J. and Doms, M. (2000) Understanding productivity: lessons from longitudinal microdata. Journal of Economic Literature 38: 569-594.

Becker, R. Gray, W., and Marvakov, J. (2016). NBER-CES Manufacturing Industry Database: Technical Notes. National Bureau of Economic Research.

Beeson, P. E., and Husted, S. (1989). Patterns and determinants of productive efficiency in state manufacturing. Journal of Regional Science, 29, 15-28.

Berndt, E.R. (1991) The Practice of Econometrics Classic and Contemporary, Addison-Wesley Publishing Company, Reading, MA.

Beveren, I.V. (2012). Total factor productivity estimation: A practical review. Journal of Economic Surveys 26 (1): 98-128

Biesebroeck, J.V. (2008) The Sensitivity of Productivity Estimates. Journal of Business \& Economic Statistics, 26:3, 311-328

Binswanger, H.P. (1974). The Measurement of Technical Change Biases with Many Factors of Production. American Economic Review, 64 (6): 964-976.

Blackorby, C., Knox L., C.A.; Thursby, M.C. (1976). Extended Hicks Neutral Technical Change. The Economic Journal. 86 (344): 845-852.

Brock, G. (2001). An econometric look at inefficiency among U.S. states. Review of Regional Studies, 31, 95-107. 
Cardarelli, R., and Lusinyan, L. (2015) U.S. Total Factor Productivity Slowdown: Evidence from the U.S. States. IMF Working Paper, WP/15/116.

Chen, C., Polemis, M., Stengos, T (2018). On the examination of non-linear relationship between market structure and performance in the US manufacturing industry. Economics Letters 164: 1-4. Christensen L.R., Jorgensen D.W, Lau L.J. (1971). Conjugate duality and the transcendental logarithmic production function. Econometrica, 39.

Christensen, L.R., Jorgenson, D.W., and Lau, L.J (1973). Transcendental Logarithmic Production Frontiers. The Review of Economics and Statistics, 55 (1): 28-45.

De Loecker, J. (2011). Product Differentiation, Multiproduct Firms, and Estimating the Impact of Trade Liberalization on Productivity. Econometrica, 79: 1407-1451.

De Loecker, J. and Konings, J. (2006) Job reallocation and productivity growth in a post-socialist economy: evidence from Slovenian manufacturing. European Journal of Political Economy 22: $388-408$.

Delis, M., Iosifidi, M., and Tsionas, E (2014). On the Estimation of Marginal Cost. Operations Research, 62(3): 543-556.

DiCiccio, T.J., Kass, R., Raftery, A., and Wasserman, L (1997). Computing Bayes Factors by Combining Simulation and Asymptotic Approximations. Journal of the American Statistical Association 92(439): 903-915.

Diewert, W. (1971). An Application of the Shephard Duality Theorem: A Generalized Leontief Production Function. Journal of Political Economy, 79(3): 481-507

Diewert, W.E., and Fox, K.J (2017). Decomposing productivity indexes into explanatory factors. European Journal of Operational Research, 256 (1): 275-291

Domazlicky, B.R., and Weber,W.L. (1998). Determinants of total factor productivity, technological change, and efficiency differentials among states, 1977-86. Review of Regional Studies, 28, 19-33.

Epure, M., Kerstens, K., and Prior D. (2011). Technology-based total factor productivity and benchmarking: New proposals and an application. Omega, 39(6): 608-619

Eslava, M., Haltiwanger, J., Kugler, A. and Kugler, M. (2004). The effects of structural reforms on productivity and profitability enhancing reallocation: evidence from Colombia. Journal of Development Economics, 75: 333-371.

Fare, R., Grosskopf, S., Norris, M., and Zhang, Z. (1994). Productivity growth, technical progress, and efficiency change in industrialized countries. American Economic Review, 84, 6683. 
Foster, L., Haltiwanger, J. and Syverson, C. (2008) Reallocation, firm turnover, and efficiency: selection on productivity or profitability? American Economic Review 98: 394-425.

Foster, L., Haltiwanger, J. and Krizan, C.J. (2006) Market selection, reallocation, and restructuring in the US retail trade sector in the 1990s. Review of Economics and Statistics 88: $748-758$.

Fuss, M., McFadden, D., and Yair, M. (1978). A Survey of Functional Forms in the Economic Analysis of Production. in: Fuss, Melvyn \& McFadden, Daniel (ed.), Production Economics: A Dual Approach to Theory and Applications, volume 1, chapter 4, North Holland.

Fuss, M., McFadden, D. (ed.), (1978). Production Economics: A Dual Approach to Theory and Applications, volume 2, North Holland.

Genius, M., Stefanou, S.E., Tzouvelekas, V. (2012). Measuring productivity growth under factor non-substitution: An application to US steam-electric power generation utilities. European Journal of Operational Research, 220: 844-852

Geweke, J. (1992). Evaluating the accuracy of sampling-based approaches to the calculation of posterior moments. In Bayesian Statistics 4, Bernardo, J. M., Berger, J. O.,

Girolami, M. and Calderhead B. (2011). Riemann manifold Langevin and Hamiltonian Monte Carlo methods. Journal of the Royal Statistical Society: Series B, 73 (2), 123-214.

Hsieh, C.T. (1999). Productivity Growth and Factor Prices in East Asia, American Economic Review, 89 (2), 133-138.

İmrohoroğlu, A., and Tüzel S. (2014) Firm-Level Productivity, Risk, and Return. Management Science, 60(8), 2073-2090.

Javorcik, B.S. (2004) Does foreign direct investment increase the productivity of domestic firms? In search of spillovers through backward linkages. American Economic Review 94: 605-627.

Jerzmanowski, M., (2007) Total Factor Productivity Differences: Appropriate Technology vs. Efficiency, European Economic Review 51: 2080-2110.

Ketteni, E., Mamuneas, T., and Stengos, T (2011). The Effect of Information Technology and human capital on economic growth. Macroeconomic Dynamics 15(05): 595-615.

Ketteni, E., Mamuneas, T., and Stengos, T. (2007). Nonlinearities in economic growth: A semiparametric approach applied to information technology data. Journal of Macroeconomics 29(3): 555-568.

Konings, J. and Vandenbussche, H. (2008) Heterogeneous responses to trade protection. Journal of International Economics 76: 371-383.

Kumbhakar, S. C., and Lovell, C. A. K. (2000). Stochastic frontier analysis. New York: Cambridge University Press. 
Kumbhakar, S.C., B.Y. Park, L. Simar, and M.G. Tsionas (2007). Nonparametric stochastic frontiers: a local maximum likelihood approach. Journal of Econometrics 137 (1), 1-27.

Lansink, A.O., Stefanou, S., and Serra, T (2015). Primal and dual dynamic Luenberger productivity indicators. European Journal of Operational Research 241 (2): 555-563

Lau, L. (1978). Application of Profit Functions. In Production Economics: A Dual Approach to Theory and Applications, Vol. 1, eds., M. Fuss and D. McFadden, pp. 133-216. Amsterdam: North Holland.

Lau L, and Tamura S. (1972). Economies of scale, technical progress, and the nonhomothetic Leontief production function: an application to the Japanese petrochemical processing industry. Journal of Political Economy, 80: 1167-1187.

Levinsohn, J. and Petrin, A. (2003) Estimating production functions using inputs to control for unobservables. Review of Economic Studies 70: 317-341.

Mairesse, J. and Jaumandreu, J. (2005) Panel-data estimates of the production function and the revenue function: what difference does it make? Scandinavian Journal of Economics 107: 651672.

Mamuneas, T., Savvides, A., and Stengos, T (2006). Economic development and the return to human capital: a smooth coefficient semiparametric approach. Journal of Applied Econometrics 21(1): 111-132.

McFadden, D. (1978). Estimation Techniques for the Elasticity of Substitution and Other Production Parameters, History of Economic Thought Chapters, in: Fuss, Melvyn \& McFadden, Daniel (ed.), Production Economics: A Dual Approach to Theory and Applications, volume 2, chapter 4 McMaster University Archive for the History of Economic Thought

G.V.L. Narasimham , P. A. V. B. Swamy and Reed R.C (1988) Productivity Analysis of U.S. Manufacturing Using a Stochastic-Coefficients Production Function. Journal of Business \& Economic Statistics, 6:3, 339-349

Olley, S.G. and Pakes, A. (1996) The dynamics of productivity in the telecommunications equipment industry. Econometrica 64: 1263-1297.

Pavcnik, N. (2002) Trade liberalization, exit, and productivity improvements: evidence from Chilean plants. Review of Economic Studies 69: 245-276.

Polemis, M., and Stengos, T. (2015). Does market structure affect labor productivity and wages? Evidence from a smooth coefficient semiparametric panel model. Economics Letters. 137(C): 182-186.

Puig-Junoy, J. (2001). Technical inefficiency and public capital in U.S. states: A stochastic frontier approach. Journal of Regional Science, 41, 75-96. 
Ramsey J.B. (1969). Tests for specification errors in classical linear least squares regression analysis. Journal of the Royal Statistical Society Series B 31:350-371.

Ray, S. C., and Desli, E. (1997). Productivity growth, technical progress, and efficiency change in industrialized countries: Comment. American Economic Review, 87, 1033-1039.

Rungsuriyawiboon, S., Stefanou, S. (2008). The dynamics of efficiency and productivity growth in U.S. electric utilities. Journal of Productivity Analysis, 30(3): 177-190

Serpa, J.C., and Krishnan, H (2017). The Impact of Supply Chains on Firm-Level Productivity. Management Science, http://dx.doi.org/10.1287/mnsc.2016.2632

Sharma, S.C., Sylweste, K., and Margono. H (2007). Decomposition of total factor productivity growth in U.S. states. The Quarterly Review of Economics and Finance, 47: 215-241.

Solow, R. (1956). A Contribution to the Theory of Economic Growth, Quarterly Journal of Econometrics, 70

Solow, R.M. (1957) Technical change and the aggregate production function. Review of Economics and Statistics 39: 312-320.

Stock, J.H., J.H. Wright and M. Yogo (2002). A Survey of Weak Instruments and Weak Identification in Generalized Method of Moments. Journal of Business and Economic Statistics $20(4), 518-529$.

Syverson, C. (2011). What Determines Productivity, Journal of Economic Literature 49(2): 326365.

Terza, J.V., A. Basu, and P.J. Rathouz (2008). Two-stage residual inclusion estimation: Addressing endogeneity in health econometric modeling. Journal of Health Economics 27 (3), $531-543$.

Tran, K., and Tsionas, E (2010). Local GMM Estimation of Semiparametric Panel Data with Smooth Coefficient Models, Econometric Reviews, 29(1): 39-61.

Tsionas, M., and Izzeldin, M (2018). A Novel Model of Costly Technical Efficiency, European Journal of Operational Research, doi: 10.1016/j.ejor.2018.01.016.

Tsionas, M., and Mamatzakis, E (2017). Adjustment costs in the technical efficiency: an application to global banking. European Journal of Operational Research. 256(2): 640-649

Van Biesebroeck, J. (2007). Robustness of productivity estimates. Journal of Industrial Economics 55: 529-569.

Varian, H (1992). Microeconomic Analysis. Third edition. W. W. Norton \& Company. 